\title{
Análise de volumes de sal em restauração estrutural: um exemplo na bacia de Santos
}

\author{
Sávio Francis de Melo Garcia ${ }^{1^{*}}$, André Danderfer Filho ${ }^{2}$, Dominique Frizon De Lamotte ${ }^{3}$, \\ Jean-Luc Rudkiewicz ${ }^{4}$
}

\begin{abstract}
Resumo A complexidade da halocinese na porção central da bacia de Santos envolve expressivas estruturas e depocentros deformados, diferenciados ao longo da direção de deformação principal. Cinco seções geológicas, com registro estratigráfico completo na área de estudo, foram restauradas para investigar diferentes estilos de deformação, incluindo a evolução da falha de Cabo Frio, coerentemente inserida na evolução tectonossedimentar da bacia de Santos. O procedimento integrou a restauração $2 \mathrm{D}$ com tratamento e análise 3D, por meio das seguintes etapas: remoção de camadas, descompactação e compensação isostática flexural; restauração desacoplada da tectônica do sal; conservação material (inclusive do sal); recomposição da sobrecarga sedimentar quando diferentes taxas de distensão afetam os domínios desacoplados; calibração batimétrica do conjunto restaurado e tratamento e análise espacial dos resultados. O detalhamento em 14 etapas de restauração foi suficiente para tratar a deformação de forma não contínua, minimizou desvios do método e produziu consistência geométrica e estratigráfica dos resultados no domínio espaço-tempo. A redistribuição controlada do sal confirmou os efeitos do aporte sedimentar e as estruturas preexistentes sobre a deformação. Os resultados demonstram a importância da reciprocidade dos efeitos de deslocamento lateral por halocinese sobre isostasia, batimetria e descompactação, não considerada nos programas de restauração existentes.
\end{abstract}

Palavras-chave: geologia estrutural; balanceamento de seções; tectônica de sal; bacia de Santos; análise de bacias.

\begin{abstract}
Analysis of salt volumes in structural restoration: an example of Santos Basin. Halokinesis complexity in the central portion of Santos Basin involves significant structures and deformed depocenters, differentiated along the tectonic transport direction. Five geological cross-sections with an entire stratigraphic record in the study area have been restored to investigate different deformation styles, including the evolution of Cabo Frio Fault, coherently inserted into the tectonosedimentary evolution of Santos Basin. The procedure combines 2D restoration with 3D treatment and analysis through the following steps: layering removal, decompaction and flexural isostatic compensation; decoupled restoration of salt tectonics; material conservation (including salt); retrieval of the layering when differential strain rates affect uncoupled domains; bathymetric calibration of the restored set, and treatment and spatial analysis of results. Detailing of 14 restoration steps has properly discretized the deformation, minimized procedure deviations, and provided geometric and stratigraphic coherence in the space-time domains. The controlled salt redistribution has confirmed the effects of sedimentary aggradation and pre-existing structures on the strain. The results highlight the reciprocity importance of the effects of the halokinetic lateral displacement on isostasy, eustasy, bathymetry, and decompaction, which was not considered in the existing restoration programs.
\end{abstract}

Keywords: structural geology; balanced restoration; salt tectonics; Santos Basin; Basin analysis.

\section{INTRODUÇÃo A deformação do sal em ba-} cias passivas está intimamente relacionada com a história de soterramento diferencial e instabilidades gravitacionais. Restaurações estruturais (tanto 2D e 3D) produzem informações valiosas para desvendar a história da deformação de uma área, a qual, inserida em um contexto mais amplo, determina as principais condições de contorno do modelo geológico.
Restaurar essa tectônica sem observar a geologia regional pode ser perigoso. A área de estudo, na porção central da bacia de Santos (Fig. 1), possui relativo equilíbrio de fluxo halocinético entre um domínio distensivo e outro compressivo: o sal migra da parte proximal, induzido pela sedimentação de plataforma, para a distal, na qual se acumula sob compressão. Esta condição permite avaliar uma premissa controversa

\footnotetext{
${ }^{1}$ Petrobras Exploração \& Produção/Exploração - E\&P-EXP, Geologia Aplicada à Exploração - GEO, Modelagem de Sistemas Petrolíferos - MSP, Rio de Janeiro (RJ); Programa de Pós-Graduação Evolução Crustal e Recursos Naturais - ECRN, Universidade Federal de Ouro Preto - UFOP, Ouro Preto (MG), Brasil; Université de Cergy-Pontoise, Cergy-Pontoise, França. E-mail: saviogarcia@petrobras.com.br

${ }^{2}$ Universidade Federal de Ouro Preto - UFOP, Ouro Preto (MG), Brasil. E-mail: andre@degeo.ufop.br

${ }^{3}$ Université de Cergy-Pontoise, Cergy-Pontoise, França. E-mail: dfrizon@u-cergy.fr

${ }^{4}$ IFP Energies Nouvelles, Rueil-Malmaison, França. E-mail: j-luc.rudkiewicz@ifpen.fr

*Autor correspondente
} 
na restauração da tectônica do sal: a conservação material da camada de sal. Além disso, o contexto regional da área permite investigações e debates sobre deformação adiastrófica, rifteamento, situação estratigráfica do sal, evolução da falha de Cabo Frio e reativação de estruturas preexistentes.

O princípio da conservação de área (ou volume) durante a deformação, considerada na restauração estrutural, perde valor se houver escape e influxo na direção de transporte ou perdas por dissolução, fenômenos comuns no sal (Jenyon 1986). Entretanto, a conservação material pode funcionar como um controle para restauração e pode ser aplicada para o sal contido em uma célula de deformação gravitacional, na qual se move de uma região para outra em equilíbrio local.

A reologia e solubilidade do sal são determinantes. O sal catalisa as deformações gravitacionais, deforma-se intensamente, desloca-se mais e para direções mais variadas do que os domínios rúpteis encaixantes (Talbot 1995). O sal sofre dissolução ao se aproximar de águas superficiais menos saturadas. Esses fenômenos explicam suficientemente as variações materiais.

Vários autores optam por não conservar materialmente o sal em seus trabalhos. Rowan (1993) ajustou a camada de sal de uma seção, sem preservação de área, entre uma base obtida por isostasia e um topo na base da sobrecarga sedimentar restaurada, supondo que a sobrecarga e o sal se reequilibram sobre a isostasia de base. Peel et al. (1995) otimizaram a espessura de sal, sem necessariamente conservar área, por meio de ajustes na superfície deposicional de referência de topo que é necessária para cada etapa de restauração da sobrecarga. Os referenciais de base e topo, independentemente da conservação material do sal, são fundamentais para sua restauração estrutural.

A abordagem 2.5D ou pseudo 3D é uma restauração estrutural por múltiplas seções. Para extrapolar a premissa de conservação aos volumes, as seções precisam ter a mesma orientação que a deformação ou o transporte tectônico. A técnica não é verdadeiramente 3D e o escape ou entrada de material, por meio das seções, constitui possível fonte de erros. A abordagem permite análises espaciais das variações de geometrias e espessuras ao longo do strike, importantes para compreender a evolução tectonossedimentar das estruturas (Grando et al. 2009). Uma ideia fundamental em restauração é que a geometria de um elemento (por exemplo, alto estrutural) mantém relação com a de outro (por exemplo, espessura da camada), e a análise de espessuras passa a ser uma ferramenta muito útil, quando os dados disponíveis são esparsos e/ou incompletos. As estruturas resultam de um processo cumulativo de deformação entre sal e sobrecarga, relativamente mais dúctil no início e mais rúptil ao final. Detalhes de interpretação como focalização, amplitude e comprimento de onda das estruturas podem revelar precursores da deformação (Hughes \& Davison 1993). Toda informação precisa estar integrada.

O presente estudo integrou compensação isostática flexural e controle de área, espessuras e evolução das janelas do sal na restauração $2 \mathrm{D}$ em cinco seções da bacia de Santos, com extrapolação e análise 3D. Os resultados 2D foram extrapolados para mapas e volumes, nos quais é possível avaliar as diferenças entre soluções independentes. A controversa premissa de conservação material do sal invoca uma discussão sobre a deformação lateral dentro e além dos limites da área de estudo, considerando-se uma célula gravitacional (área de estudo) e a bacia como um todo.

\section{CONTEXTO GEOLÓGICO DA BACIA DE} SANTOS A bacia de Santos é do tipo margem passiva situada na margem continental Leste do Brasil, entre os paralelos 23 e $30^{\circ} \mathrm{S}$. Faz limite com a bacia de Pelotas, no alto de Florianópolis e com a de Campos, no alto de Cabo Frio. Abrange uma área de $352.000 \mathrm{~km}^{2}$ até a cota batimétrica de $3.000 \mathrm{~m}$ (Fig. 1). Resulta da partição do continente Gondwana no Eocretáceo e, mais larga do que sua correspondente na margem africana, avança cerca de $700 \mathrm{~km}$ além da costa. Sua geometria é moldada pela interação dos esforços distensionais com descontinuidades do embasamento (Zalán et al. 2009). Seus espessos evaporitos

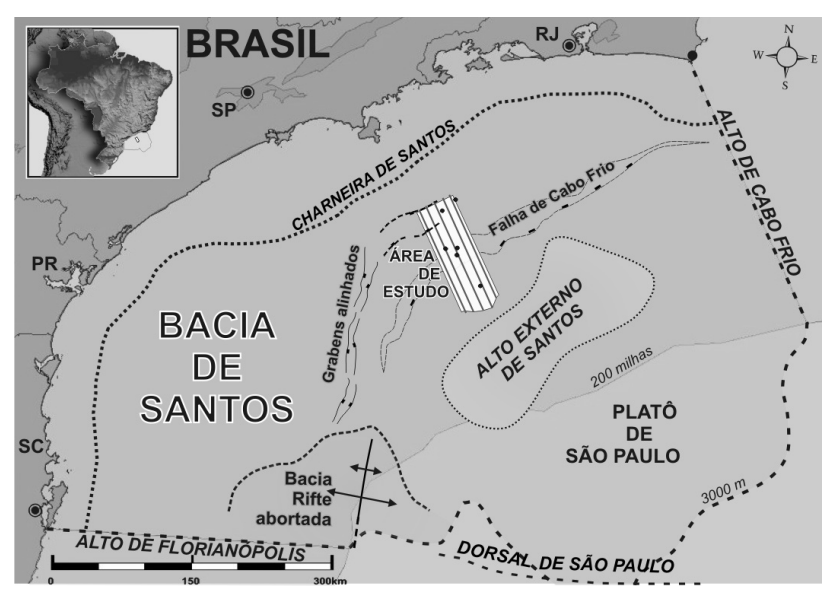

Figura 1 - Mapa de localização e feições estruturais da bacia de Santos. 
representam o extremo Sul da bacia evaporítica aptiana do Atlântico Sul, elemento importante para a evolução de tal margem passiva (Mohriak 2001).

Estratigrafia $\mathrm{O}$ arcabouço estratigráfico utilizado baseia-se em Moreira et al. (2007), como observado na Fig. 2. O embasamento, composto por granitos, gnaisses e metassedimentos neoproterozoicos da Província Mantiqueira, aflora no continente. A espessura sedimentar máxima esperada de 12.000 m ocorre na área de estudo. Os quatro grupos caracterizados, Guaratiba, Camburi, Frade e Itamambuca, registram ruptura crustal seguida de deriva continental.

O registro sedimentar começa pelo Grupo Guaratiba, depositado durante o rifte e o pós-rifte, sob falhamentos ativos controlando meio-grabens e blocos rotacionados. Os basaltos da Formação Camboriú definem o embasamento econômico. Carbonatos, siliciclásticos e evaporitos das formações Piçarras, Itapema, Barra Velha e Ariri complementam o Grupo Guaratiba. A atividade tectônica diminui na fase pósrifte (Eoaptiano) em transição do ambiente continental ao marinho raso. Os evaporitos da Formação Ariri (Aptiano) acumulam mais de $2000 \mathrm{~m}$ de espessura, depositados em um curto período (Chang et al. 1990).

A fase de deriva continental se superpõe ao Grupo Guaratiba. É composta pelos grupos Camburi, Frade e Itamambuca, intensamente deformados pela tectônica do sal subjacente.

O Grupo Camburi (Albo-Cenomaniano) representa o início da transgressão marinha na bacia de Santos. A deposição no Albiano é caracterizada por siliciclásticos e carbonatos de águas rasas na plataforma continental e por margas e folhelhos na região

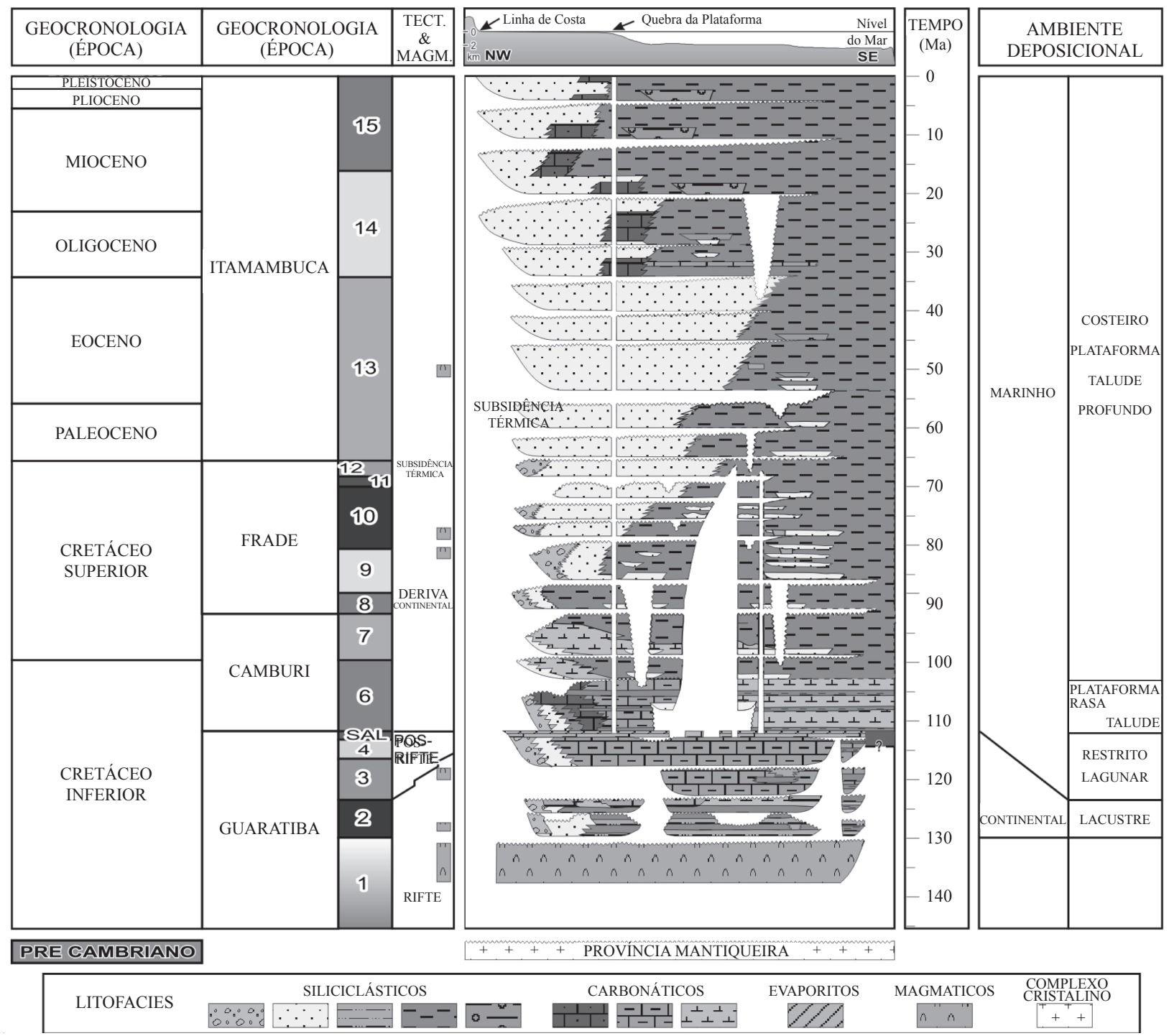

Figura 2 - Carta estratigráfica da bacia de Santos e horizontes usados na restauração estrutural, modificada de Moreira et al. (2007). 
distal mais profunda. O Cenomaniano registra siliciclásticos deltaicos e aluviais em leques proximais, passando a folhelhos e margas de plataforma nas regiões distais, com turbiditos arenosos nos baixos tectonicamente controlados.

O Grupo Frade registra um episódio de progradação siliciclástica do Cretáceo Superior quando os limites da plataforma continental avançam sobre o oceano por cerca de $200 \mathrm{~km}$ para o Leste.

Uma discordância separa os grupos Frade e Itamambuca. Os depósitos marinhos do Grupo Itamambuca (Cenozoico) compreendem leques aluviais proximais, folhelhos e arenitos distais, com ocorrências de carbonatos plataformais próximas à quebra do talude.

Quinze horizontes, baseados nesta estratigrafia, estão interpretados em cinco seções geológicas (AA', BB', CC', DD' e EE') com 120 km de comprimento médio cada e menos de $10 \mathrm{~km}$ distantes entre si (Fig. 3), restauradas por técnicas 2D, extrapoladas para superfícies e analisadas em 3D.

Arcabouço regional O processo de ruptura que levou à abertura do Oceano Atlântico imprime as principais feições estruturais da bacia de Santos (Fig. 1).

O platô de São Paulo, uma feição fisiográfica de destaque nas águas profundas do Atlântico Sul (Mascle \& Renard 1976, Guimarães et al. 1982, Demercian 1996, Gomes et al. 2002), constitui-se de crosta continental estirada. Um braço de rifte abortado projeta-se na parte Sul do platô de São Paulo, entre o alto de Florianópolis e a dorsal de São Paulo (Mohriak 2001). Uma sequência de grabens alinhados propaga este braço para o Norte e depois continua na orientação SW-NE, alinhado ao baixo estrutural observado nas seções geológicas (Fig. 1).

O rifteamento ocorreu até o Eocretáceo, com manifestações magmáticas. A compartimentação sedimentar, provavelmente controlada por zonas de cisalhamento mais frágeis tangidas pelo afinamento crustal (Zalán et al. 2009), aproveita estruturas preexistentes. A seção rifte é predominantemente controlada por falhas normais SW-NE. As reativações destas estruturas controlaram o desenvolvimento de cadeias de montanhas costeiras (Serra do Mar e da Mantiqueira) e de grabens continentais durante o Cenozoico (Almeida 1976, Zalán \& Oliveira 2005). O papel de tais reativações sobre o desenvolvimento de falhas da fase de deriva pode estar encoberto pela deformação dúctil da camada de sal, mas o relevo herdado é certamente importante. As maiores espessuras sedimentares ocorrem no baixo estrutural SW-NE da área de estudo. O paralelismo com a falha de Cabo Frio demonstra o controle superimposto às principais feições halotectônicas (Figs. 1 e 3).

O alinhamento do alto de Florianópolis e da Dorsal de São Paulo proporcionou as condições de desenvolvimento da vasta bacia evaporítica do Atlântico Sul. Estas estruturas barraram a circulação do oceano Atlântico já coexistente mais ao Sul, na bacia de Pelotas (Demercian 1996). Um relevo preexistente, não necessariamente igual ao do volume

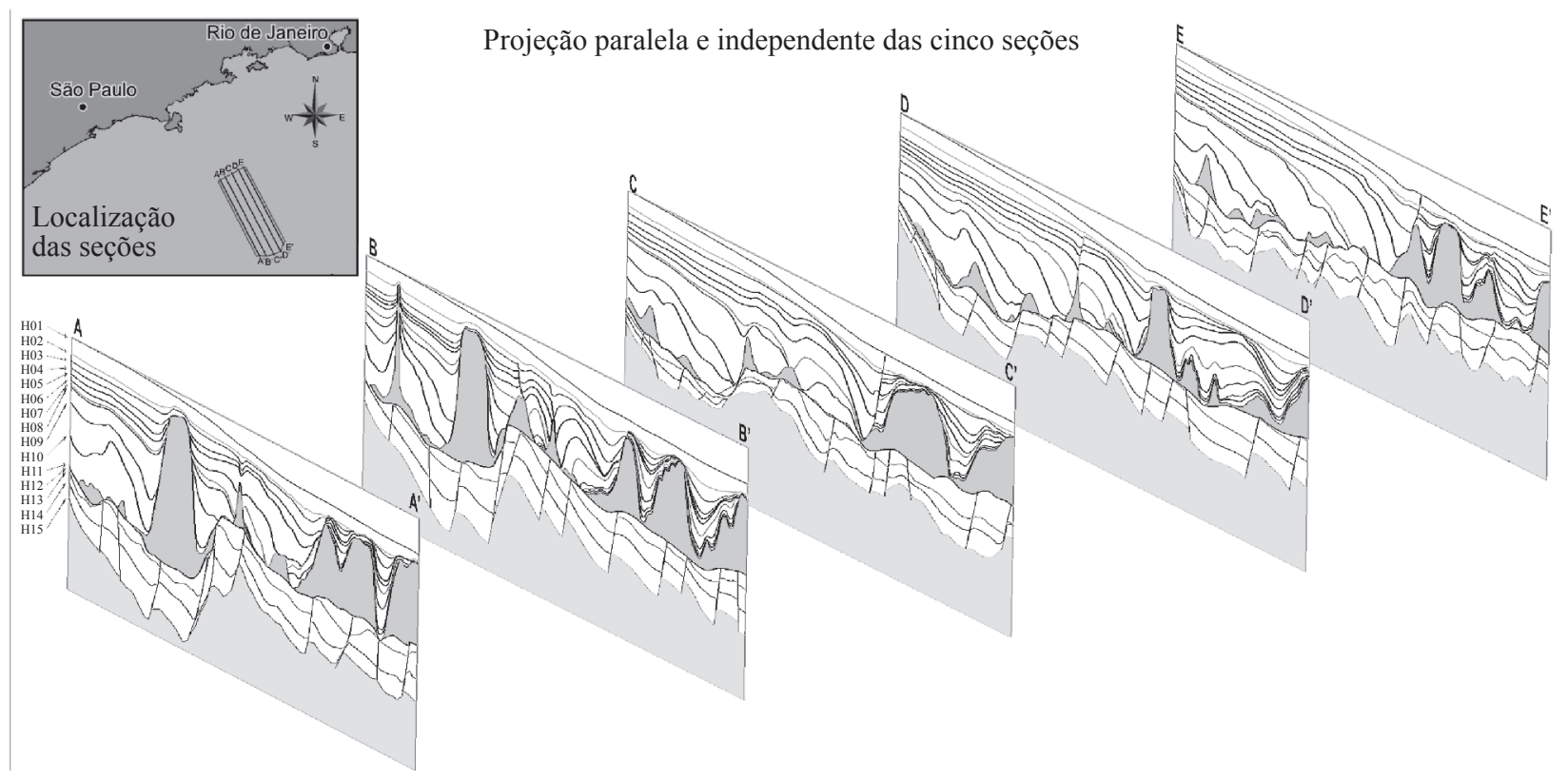

Figura 3 - Perspectiva das seções geológicas. 
de sal a depositar (como postulado por Montaron \& Tapponnier 2010), permitiu a deposição de mais de $2.000 \mathrm{~m}$ de sal em curto período (entre 0,5 e $1 \mathrm{Ma}$ ) no Aptiano superior. A carga sedimentar do próprio sal induziu um pulso superior a $1.000 \mathrm{~m}$ de subsidência isostática regional (Garcia et al. 2012), e o bloqueio das águas oceânicas adjacentes persistiu à subsidência somente o necessário para a deposição do sal.

A tectônica de sal começa ainda no Aptiano superior devido às irregularidades do relevo de base preexistente, às variações na espessura do sal e ao soterramento diferencial (Demercian 1996, Garcia 1999). A sedimentação marinha progradou sobre o sal desenvolvendo batimetrias relativamente rasas na bacia de Santos. A configuração radialmente convergente da sedimentação controlou a tectônica do sal a partir da linha de Charneira de Santos, promovendo um aumento da compressão em direção ao centro da convergência no platô de São Paulo (Cobbold \& Szatmari 1991). A complexidade da direção de transporte sedimentar se reflete na migração de depocentros, observada por Assine et al. (2008). Esses aspectos parecem relativamente compensados na área de estudo da porção central da bacia, com a prevalência local de uma direção principal de transporte ao longo do mergulho (dip).

Guerra (2008) sugere que a falha de Cabo Frio (Fig. 4) teria controlado a evolução do maior depocentro nesta porção da bacia desde o final do Turoniano. Essa falha marca a transição entre distensão e compressão halotectônicas. A progradação proximal promove falhas de crescimento predominantemente antitéticas, enquanto as minibacias clássicas distais se estabelecem sob compressão (Mohriak \& Szatmari 2001). A camada de sal é inflada pela espessa sedimentação proximal, e o diapirismo reativo na região distal inibe o espaço de acomodação e permite apenas uma sedimentação mais delgada (Ge et al. 1997). As minibacias evoluem por fluxos sedimentares mais intensos que ultrapassam o talude e, somente com a relativa desaceleração da tectônica de sal ao final do Neocretáceo, estas minibacias evoluem mais significativamente. Ainda que diversos dos autores mencionados interpretem deslocamentos de dezenas de quilômetros na falha de Cabo Frio, Freitas (2006) interpretou um pouco além desta falha uma espessa coluna de sal, cujo acamamento deposicional estaria preservado de deformação.

MATERIAIS E MÉTODOS Um conjunto de cinco linhas sísmicas em profundidade permitiu a elaboração e a restauração estrutural 2D de seções geológicas na direção principal do transporte da área de estudo. Dois programas foram utilizados para interpretação 2D (gOcad), restauração estrutural 2D (ReconMS, propriedade Petrobras) e análise espacial 3D (gOcad). Seis poços exploratórios disponíveis deram suporte à correlação estratigráfica dos horizontes interpretados.

Dados geológicos Os 15 horizontes estratigráficos e as diversas falhas interpretadas na sísmica representam a evolução espaçotemporal da bacia de Santos, em conformidade com a carta estratigráfica

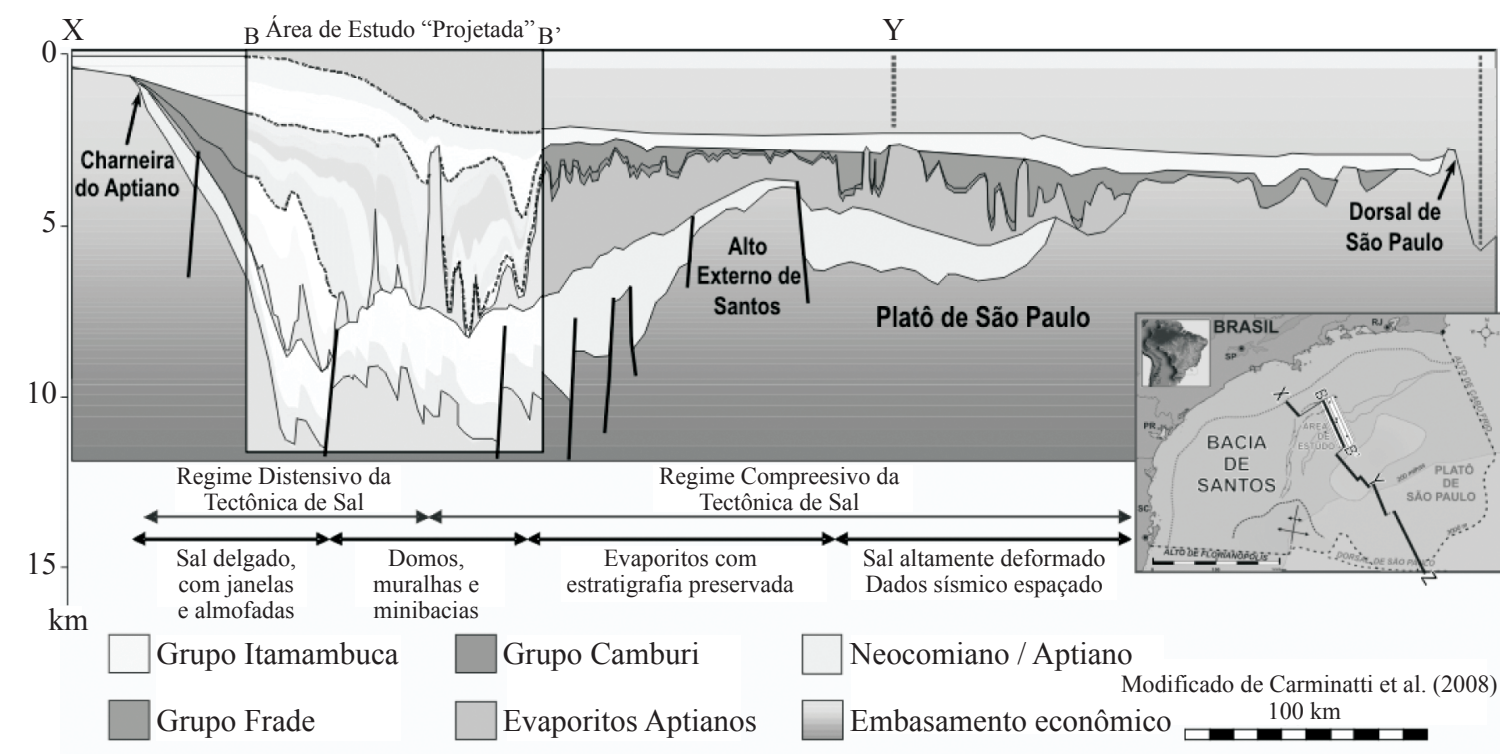

Figura 4 - Seção regional da bacia de Santos (XYZ) e projeção da área de estudo (BB'). 
de Moreira et al. (2007), como observado na Fig. 2. As linhas sísmicas disponíveis, afastadas cerca de 9 $\mathrm{km}$ umas das outras, apresentam baixa qualidade e resolução. Dois dos seis poços disponíveis para correlação estão na plataforma rasa, três na região do talude e apenas um, que não dispõe de dados bioestratigráficos, está em águas profundas (Fig. 1). Certamente, detalhes e estruturas menores não foram observados, mas as principais falhas (com destaque para a de Cabo Frio) estão identificadas com clare$\mathrm{za}$, as variações de espessamento das camadas sinalizam depocentros coerentes e diferentes domínios estruturais são observados. Os dados são suficientes para detalhar fácies ao longo das seções e restaurar efeitos de compactação diferencial. O detalhamento faciológico minimiza também falsos efeitos de compactação nos rejeitos de falhas ao longo do tempo. A camada de sal não é descompactada, pois o sal possui porosidade desprezível.

\section{Ferramentas numéricas de restauração estrutural}

Há mais de 20 anos que restaurações computadorizadas contribuem para elucidar a complexidade da tectônica de sal. A técnica evoluiu para o domínio 3D, mas a maioria dos estudos ainda trata estruturas e deformações aproximadamente cilíndricas, limitadas no trato da deformação complexa. A aplicação 2D continua sendo uma ferramenta analítica e conceitual robusta para inúmeros casos, e sua aplicação integrada com técnicas 3D amplia as possibilidades de observação e interpretação da cinemática da deformação complexa (Richards et al. 2003, Domzig et al. 2010). As premissas de deformação ao longo do transporte tectônico continuam valendo para transpor resultados e interpretações do domínio 2D para o 3D, bem como ditam as maiores limitações de ambos os métodos. A abordagem proposta para as aplicações 2D e 3D oferece várias possibilidades de avaliação, análise espacial e integração de procedimentos, no escopo do estudo de uma deformação regional.

Transformações de restauração 2D, conhecidas como cisalhamento simples ou deslizamento flexural, suficientes à restauração do sal, estão implementadas no ReconMS, com diferencial no detalhamento faciológico para descompactação e da isostasia como controle referencial (Roberts et al. 1998, Bender et al. 1989, Watts 2001, Santi 2002). A solução isostática com compensação flexural sobre a litosfera aproxima melhor o efeito regional da carga ou descarga sedimentar.
O gOcad (Université de Nancy, França) extrapola a restauração ao ambiente $3 \mathrm{D}$, permite quantificar volumetricamente a deformação ao longo do tempo e avaliar as premissas utilizadas. A visualização 3D favorece a compreensão espacial dos procedimentos e da evolução estrutural da área de estudo.

\section{Procedimentos de restauração e análise estrutural}

Os procedimentos de interpretação, tratamento dos dados e restauração estrutural das seções neste trabalho assemelham-se aos de Garcia et al. (2012). O objetivo é traçar um cenário evolutivo da tectônica de sal, por meio da restauração estrutural 2D integrada à análise 3D.

A interpretação dos horizontes em sísmica foi realizada no gOcad. Topo e base do sal são refletores destacados de fácil interpretação, e as principais discordâncias acima do sal apresentam distribuição ampla e rastreamento confiável. A baixa qualidade das linhas sísmicas (sinais múltiplos e ruídos) prejudica a interpretação dos horizontes e das falhas mais profundas (seção pré-sal). A coerência topológica dos horizontes, da movimentação e dos rejeitos das falhas deve ser checada antes de ser iniciada a restauração. O detalhamento faciológico foi definido por meio da integração de dados dos poços, de sismofácies e dos modelos deposicionais de Moreira et al. (2007). Cinco seções geológicas resultantes da interpretação passaram para as etapas de restauração estrutural seguintes.

\section{RESTAURAÇÃO DESACOPLADA DA DEFORMA-} ÇÃO PELO SAL A restauração estrutural trata, de forma desacoplada, as deformações do sal (thinskinned) e das camadas abaixo do sal (rifteamento). O sal trabalha como elemento de acomodação dos espaços. A Fig. 5 esquematiza as etapas da restauração:

- remoção da camada mais superficial com compensação isostática flexural e descompactação das camadas subjacentes;

- $\quad$ abstração da camada de sal para ajuste de uma geometria modelo referencial de topo;

- $\quad$ restauração livre da deformação por falhas e sal;

- $\quad$ reinserção do sal observando sua conservação de área sob as camadas restauradas e a coerência de espessuras e estilo da deformação;

- $\quad$ recomposição, por extrapolação regional, da parte distal vacante na seção a fim de reequilibrá-la para remoção da camada seguinte; 


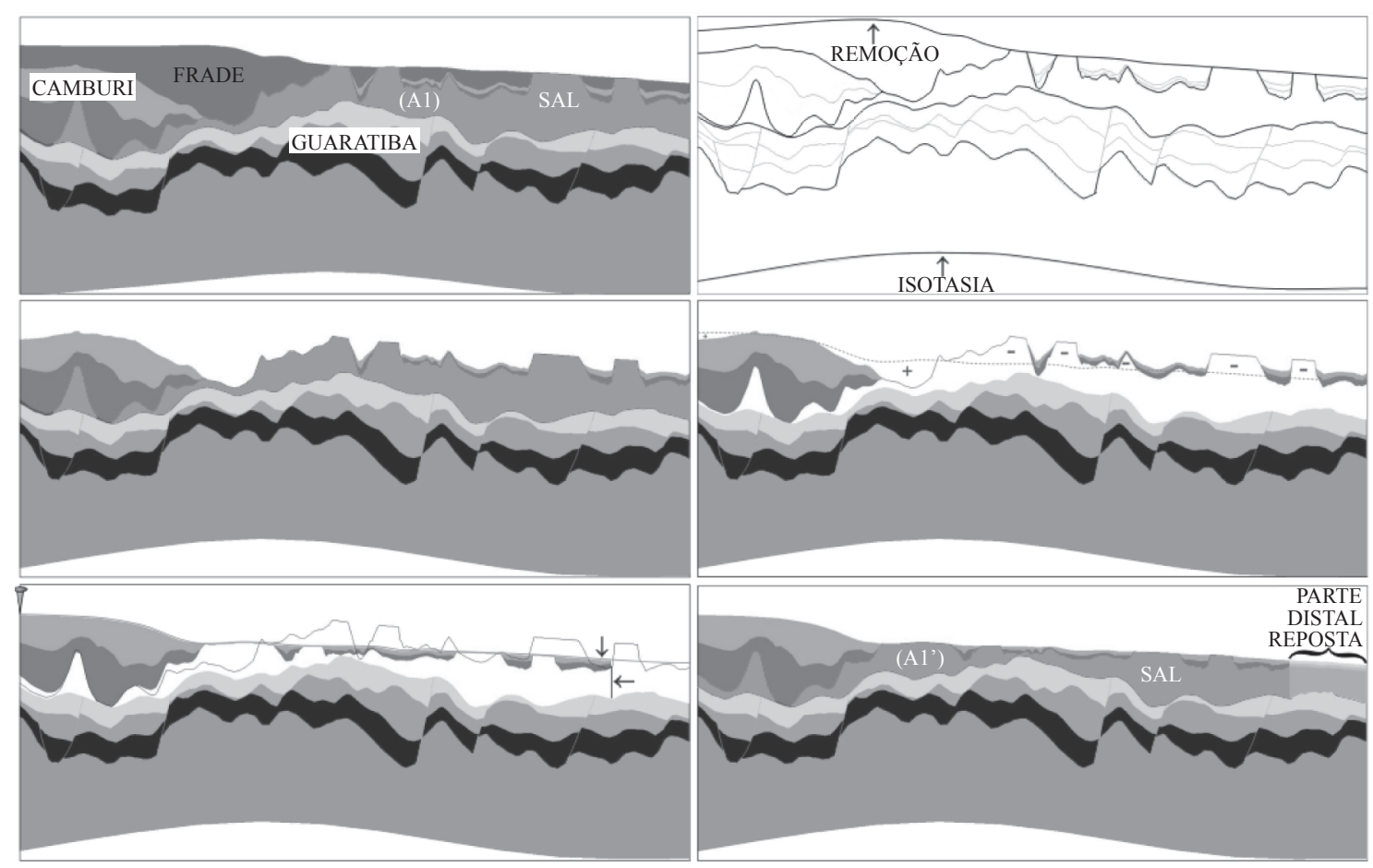

Figura 5 - Exemplo das etapas de restauração estrutural.

- $\quad$ calibração de paleobatimetria do conjunto restaurado, por ser realizada ao final, esta calibração será discutida adiante e não está na figura.

Um ponto fixo imposto junto à borda proximal de cada seção despreza a pequena distensão observada à montante da área de estudo. $\mathrm{O}$ relevo remanescente após a remoção de uma camada sugere onde houve abertura de espaço para a acomodação dos sedimentos da mesma $(+)$ e onde houve inflação da camada de sal (-). A área do sal, sob a camada removida (A1), é conservada abaixo do conjunto remanescente restaurado (A1'). Embora esta conservação seja controversa, funciona como elemento de controle de incertezas na restauração estrutural da seção. O balanço dos espaços movimentados não é trivial, e a premissa condiciona os reajustes na batimetria $(\downarrow)$ e na distensão $(\leftarrow)$.

O grau de liberdade é menor na restauração das camadas mais recentes (grupos Itamambuca e Frade), pois as janelas de sal (salt welding) fazem esta restrição. A espessura do sal não deve variar aleatoriamente durante a restauração e esta variação é acompanhada por geo-história restaurada $1 \mathrm{D}$, procedimento apresentado em Garcia et al. (2012).

A restauração das camadas abaixo do sal reflete a dificuldade de interpretação e a falta de dados. Essa foi realizada por descompactação, restauração dos movimentos ao longo das falhas e rotação do conjunto para ajustá-lo ao nível batimétrico regional, sem paleogeometria modelo.

\section{CONDICIONANTES ISOSTÁTICOS Cálculos de} descompactação e isostasia flexural após remoção da sobrecarga em cada etapa seguem a formulação de Bender et al. (1989). A solução é um cálculo discreto uniformemente distribuído ao longo da seção, de forma a considerar cada estrutura importante para depois interpolar.

Valores de espessura de rigidez elástica $\left(\mathrm{T}_{\mathrm{e}}\right)$ de $5 \mathrm{~km}$ e de densidade da crosta de $2,78 \mathrm{~g} / \mathrm{cm}^{3}$ foram considerados na parametrização. Um valor $\mathrm{T}_{\mathrm{e}}$ constante é aplicado ao longo de cada seção. A opção de manter um único valor ao longo do tempo teve a pretensão de simplificar o procedimento e encontrar similares em outros trabalhos publicados (Roberts et al. 1998).

A carga sedimentar da área de estudo (cerca de apenas $120 \mathrm{~km}$ ) subestima o efeito da carga sedimentar da bacia (mais de $600 \mathrm{~km}$ da costa à Dorsal de São Paulo) sobre a litosfera. O artifício para minimizar erros foi extrapolar a geologia regional em cada seção para ambos os lados.

Se as operações de restauração são etapas independentes dos cálculos de descompactação e isostasia, seus efeitos não são compensados. Um ensaio sobre a seção regional da bacia mostra com exagero a magnitude deste desequilíbrio (Fig. 6) e está descrito nos resultados desta pesquisa. 


\section{CONDICIONANTES PALEOTOPOGRÁFICOS Um} perfil paleodeposicional é necessário para referenciar a restauração das camadas após cada descompactação. Uma superfície similar à do presente, composta de plataforma rasa, talude e águas profundas, foi interpretada para as camadas deformadas pelo sal por meio de sismofácies e geometria (Fig. 7). Os pontos interpretados para a quebra da plataforma e pé do talude são coerentes com o arcabouço estratigráfico e a evolução da linha de costa (Lavorante \& Ebert 2005). Acompanhados ao longo da restauração, estes pontos condicionam a superfície paleodeposicional em cada etapa.

O cálculo isostático e a paleossuperfície não estabelecem valores batimétricos absolutos, cuja calibração é realizada ao final da restauração. Os poços utilizados na calibração batimétrica não atravessam a seção sedimentar, e seus sumários bioestratigráficos permitem ajuste de baixa resolução, com incertezas de centenas a milhares de metros para diferentes ambientes marinhos. Perfis regionais de paleobatimetria foram estabelecidos a partir da bioestratigrafia dos cinco poços, com extrapolação para a região batial onde não há dados (Fig. 8).
A abordagem de restauração não considera erosão, eustasia, resfriamento térmico e compensação isostática de cargas sedimentares reposicionadas após a restauração. As erosões existem e foram observadas na área de estudo, mas nenhuma de grande magnitude foi interpretada.

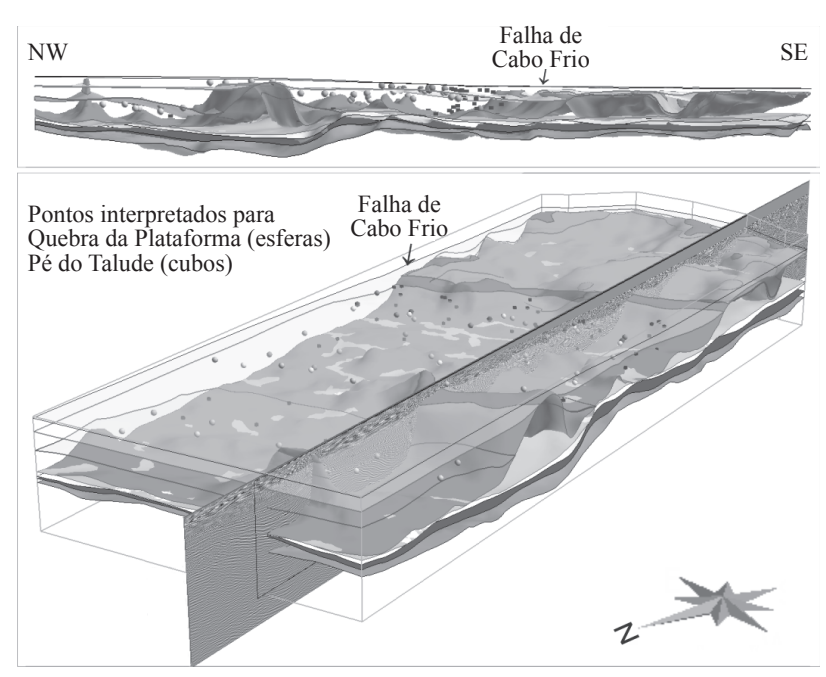

Figura 7 - Pontos da quebra da plataforma e pé do talude, interpretados em sísmica.

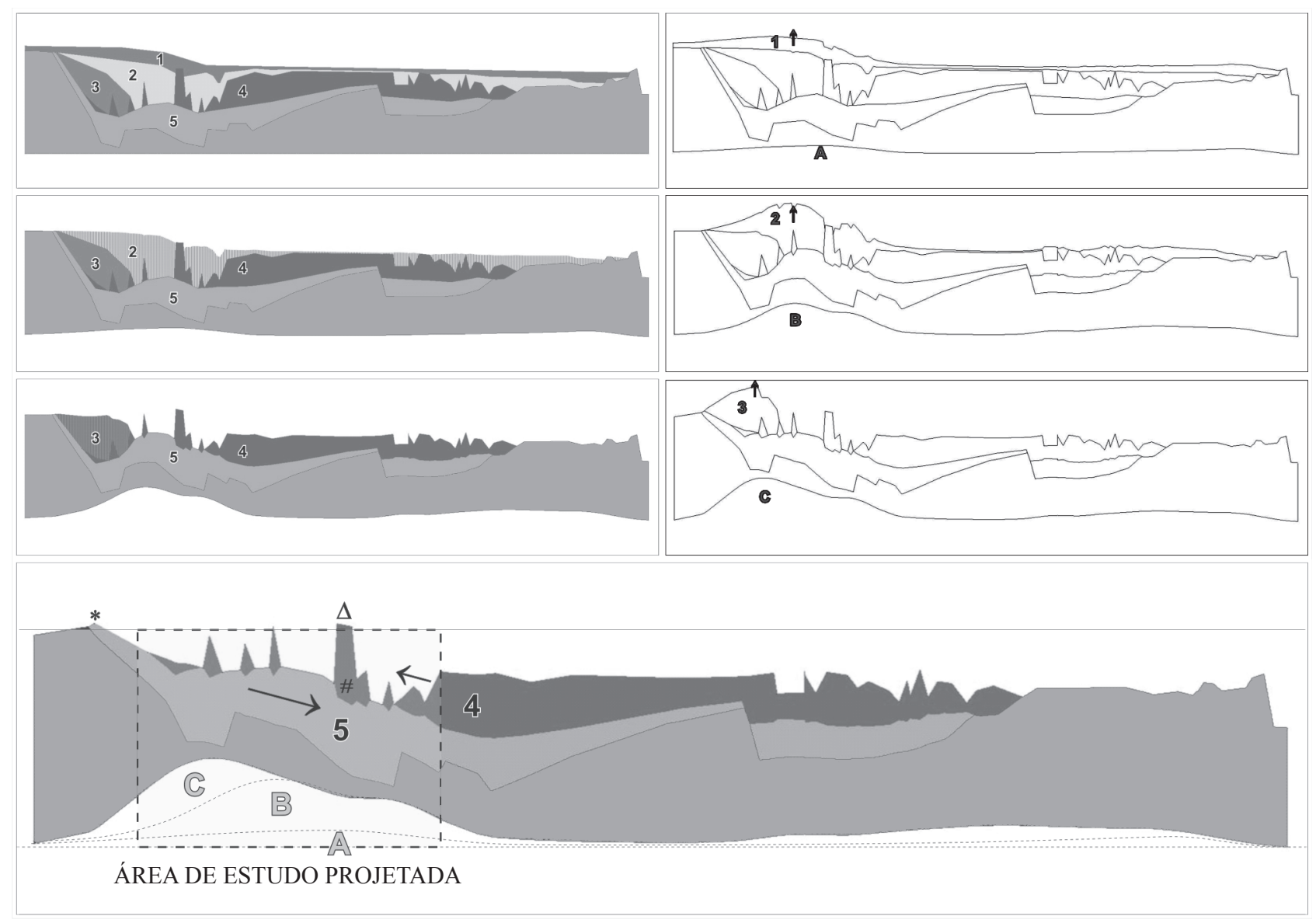

Figura 6 - Efeitos de isostasia flexural sobre seção regional da bacia de Santos. A isostasia acumulada $(A+B+C)$ está exagerada, onde significativa sobrecarga sedimentar foi removida, subestimada sob o sal não restaurado ao centro da seção (D) que, se restaurado, aliviaria a sobrecarga. 


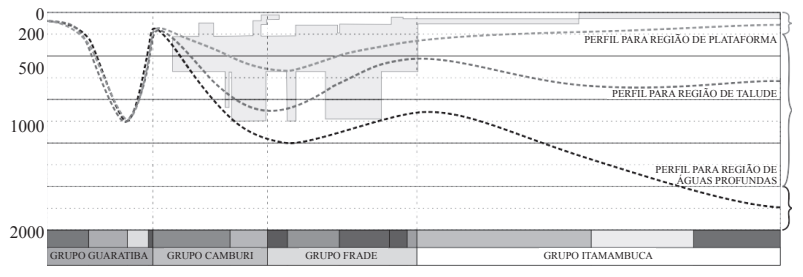

Figura 8 - Perfis regionais de evolução paleobatimétrica.

ANÁLISE ESPACIAL DA RESTAURAÇÃO ESTRUTU$R A L \quad$ O resultado da restauração independente de cada seção é, após a calibração batimétrica regional, transferido para o ambiente tridimensional do gOcad. Os resultados geram superfícies bastante suavizadas no domínio 3D, devido ao grande espaçamento. Nenhum controle elaborado é aplicado na extrapolação, apenas o cuidado de eliminar isópacas negativas. A área de estudo extrapola lateralmente as seções AA' e EE' para definir um volume em relação às cinco seções. As superfícies do topo e base do sal de cada estágio restaurado são, então, analisadas e mensuradas para análise da movimentação, dos volumes e das taxas de deformação do sal na área de estudo.

\section{RESULTADOS O resultado da restauração} estrutural é apresentado em diferentes momentos do início do rifteamento até o presente. Soluções que viabilizaram o procedimento proposto também estão discutidas a seguir.

\section{Ensaio de isostasia flexural $\mathrm{O}$ ensaio realizado} com a seção da bacia de Santos, de Carminatti et al. (2008), ilustra as distorções isostáticas acumuladas quando nenhuma restauração estrutural é processada (Fig. 6). A remoção e a descompactação dos grupos Itamambuca (1), Frade (2) e Camburi (3) produzem as respostas isostáticas acumuladas A, B e C. O efeito da progradação sobre a isostasia seria diferente se $\mathrm{O}$ deslocamento gravitacional da camada de sal $(\leftarrow 4)$ estivesse restaurado. $\mathrm{O}$ resultado sugere que havia uma rampa $(\rightarrow)$ na base do sal, que foi transformada em um baixo estrutural no tempo presente por $12.000 \mathrm{~m}$ de sobrecarga sedimentar. As distorções incluem compactação diferencial (\#), subjacentes a montanhas de sal $(\Delta)$, e um relevo de ombreira $(*)$.

Outro ensaio testou o valor de espessura elástica $\left(\mathrm{T}_{\mathrm{e}}\right)$ no cálculo da compensação flexural. Valores de $\mathrm{T}_{\mathrm{e}} \mathrm{de}$ 5 e $20 \mathrm{~km}$ não produziram diferenças regionais de grande magnitude na remoção de uma única camada. $O$ resultado destacou apenas diferenças locais, sob as maiores estruturas de sal e crescimento sedimentar individualizadas

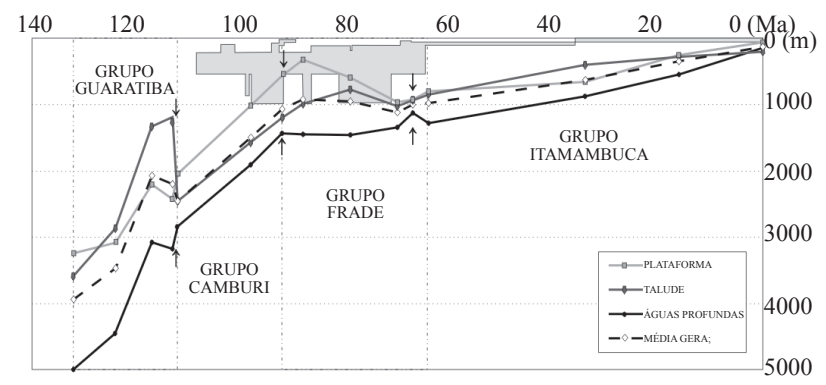

Figura 9-Diferenças médias entre resultado isostático e perfil batimétrico, acumuladas no tempo.

no comprimento de onda de dezena de quilômetros, com amplitudes de até 50 metros para compensação isostática de $\mathrm{T}_{\mathrm{e}}$ de $5 \mathrm{~km}$. Este valor de $\mathrm{T}_{\mathrm{e}}$ aproxima o procedimento ao modelo de Airy e permite uma compensação flexural mais sensível sob as estruturas halotectônicas. Entretanto, nenhum outro ensaio foi realizado para averiguar as diferenças cumulativas na remoção sucessiva de camadas. Uma análise mais rigorosa dos valores de $\mathrm{T}_{\mathrm{e}}$ exigiria também considerar uma discussão sobre os efeitos térmicos da ruptura litosférica (Watts 2001), o que não foi possível realizar neste trabalho.

Calibração paleobatimétrica A calibração batimétrica foi realizada ao final da restauração estrutural, e o cálculo isostático acumulou diferenças ao longo do tempo. A resposta puramente isostática foi analisada por meio de 15 pontos distintos, 3 em cada seção, situados a $15 \mathrm{~km}$ (plataforma), $50 \mathrm{~km}$ (talude) e $105 \mathrm{~km}$ (águas profundas) e comparada ao perfil regional esperado (Fig. 8). A diferença da resposta média, para cada domínio em relação a este perfil (Fig. 9), foi extrapolada em mapas e aplicada em cada etapa para correção batimétrica dos cenários restaurados. A linha tracejada expressa a média geral destas diferenças. $\mathrm{O}$ efeito acumulativo das incorreções isostáticas e as incertezas batimétricas aumentam para o passado e justificam um fator de suavização adicional também crescente em relação à média no passado. A incerteza da batimetria nos poços está assinalada nas áreas em cinza na Fig. 9 e permite compará-la às diferenças isostáticas.

As discordâncias que limitam os grupos Guaratiba (112 Ma), Camburi (92 Ma) e Frade (64 Ma) ilustram situações notáveis ao ajuste batimétrico nas restaurações (Fig. 9). Não por coincidência, corresponde à dificuldade encontrada para restaurar cada megassequência estratigráfica, com destaque para a própria deposição do sal, com maior taxa de deposição na bacia de Santos, entre 112 e 113 Ma. 


\section{Arcabouço estrutural investigado $\mathrm{O}$ arcabouço} estrutural está registrado nas cinco seções AA', BB', CC', DD' e EE' restauradas, bem como nas superfícies e nos volumes extrapolados para cada momento restaurado.

O modelo apresenta maior incerteza de interpretação nas camadas mais profundas, devido à baixa qualidade e ao espaçamento do dado sísmico. $\mathrm{O}$ arcabouço das camadas abaixo do sal foi obtido a partir de traços pouco contínuos, sem possibilidade de garantir a continuidade lateral para as estruturas mais profundas (Fig. 10). Esse arcabouço é um mosaico de estruturas pequenas de papel obscuro na evolução tectônica, com depocentros compartimentados por falhas em grabens assimétricos.

Destacam-se um alto e um baixo estrutural de maior expressão regional e consistência evolutiva. Tais estruturas acompanham a principal estruturação NE-SW do embasamento e perdem magnitude de SW para NE. A região do baixo estrutural controla os maiores depocentros do rifte e pós-rifte, em particular no compartimento $\mathrm{W}$, de expressão mais profunda nas seções AA' e BB'. A relação deste compartimento mais espesso para a situação mais delgada na seção CC' e a diferenciação de geometria da falha de borda do baixo nas seções AA' e BB' inferem a existência de uma estrutura NNW, subparalela às seções geológicas. No alto estrutural das seções AA' e BB', um espessamento das camadas está aparentemente controlado pela estrutura NNW, expressando a complexidade das estruturas profundas e sugerindo maior extensão lateral do compartimento $\mathrm{W}$.

A base do sal, na região do alto estrutural, reflete uma forma suavizada do embasamento (Fig. 11). Essa estrutura coloca em questão a premissa de evolução estrutural desacoplada entre a tectônica das fases rifte e pós-rifte (envolvendo embasamento), em relação à deriva (deformação por halocinese). As falhas do embasamento tangenciam a base do sal nas seções AA' e BB'. O relevo herdado do embasamento controlou a deposição do sal, que, atualmente, mesmo deformado e

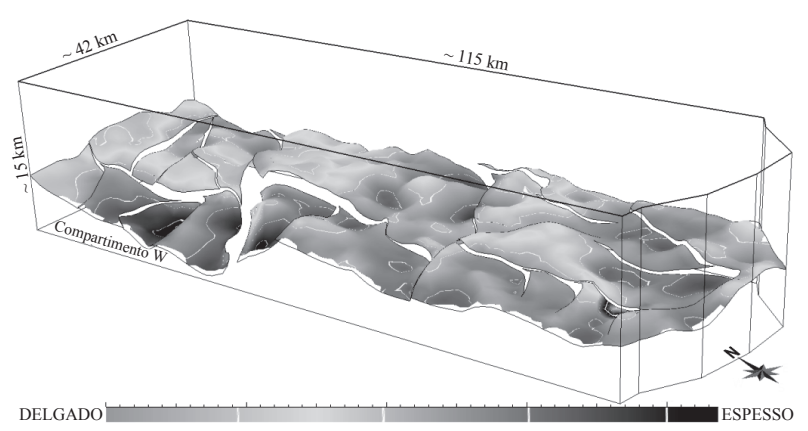

Figura 10 - Relevo do embasamento, projetada espessura da seção pré-sal. descontínuo, tem estruturas maiores e mais espessas no baixo estrutural no compartimento W. Muralhas amalgamadas confinam as minibacias na região distal.

Os grupos Camburi, Frade e Itamambuca refletem o controle da progradação sedimentar sobre a movimentação do sal (Fig. 12). As maiores espessuras proximais também são observadas no compartimento W das seções AA' e BB', com o relevo preexistente

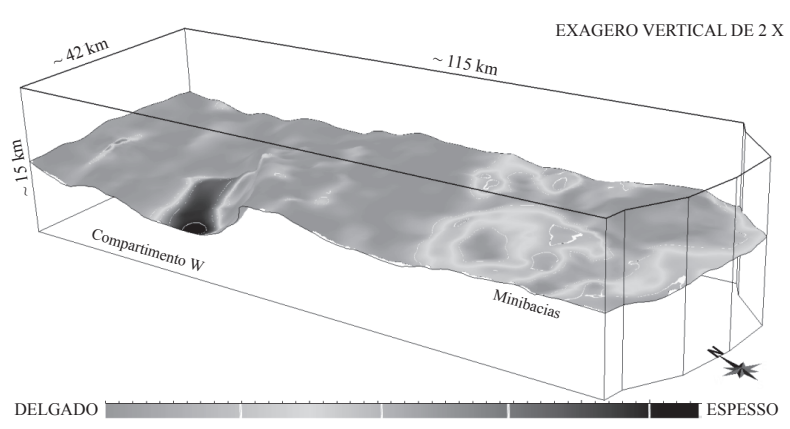

Figura 11 - Base dos evaporitos, projetada espessura do sal.

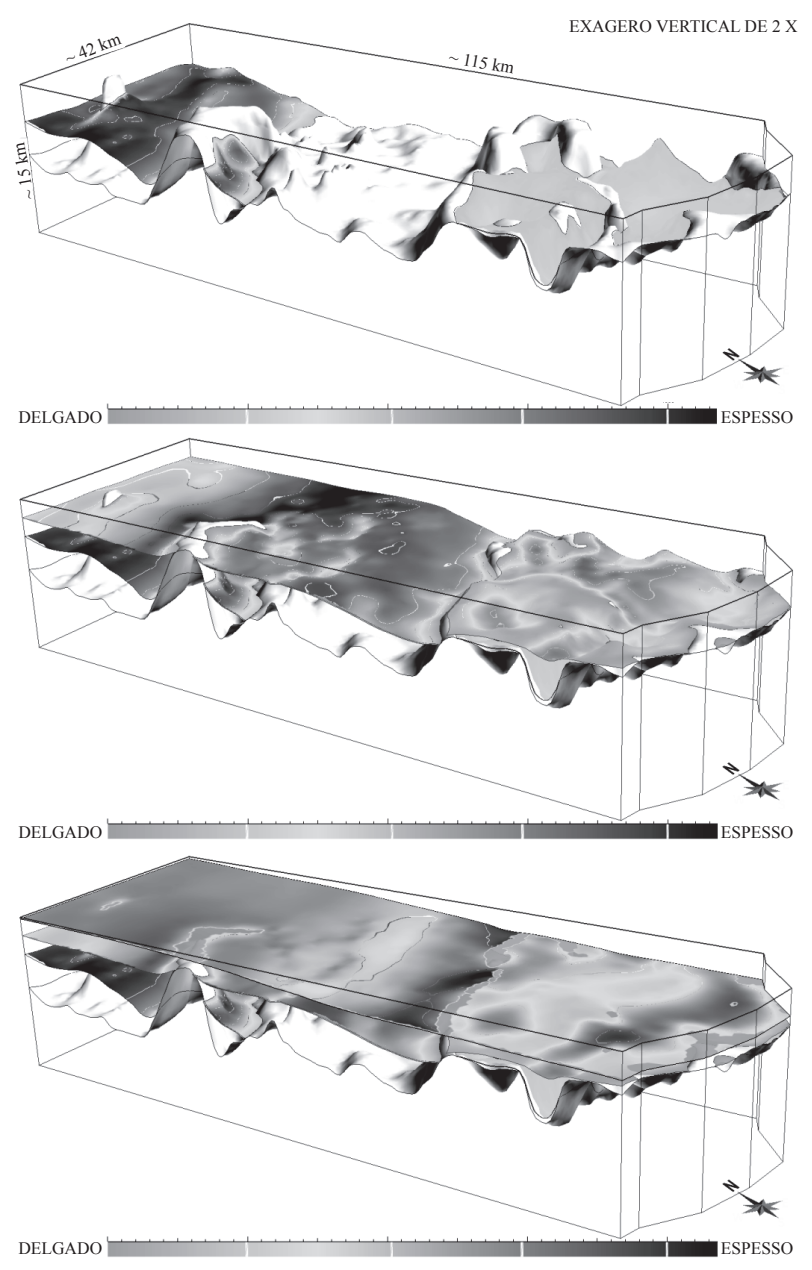

Figura 12 - Isópacas dos grupos Camburi (A), Frade (B) e Itamambuca (C) projetadas nos respectivos topos demonstrando a progradação sobre a falha de Cabo Frio. 
trabalhando como anteparo ao avanço da sedimentação. A falha de Cabo Frio atravessa a área de estudo na orientação SW-NE e tem seu desenvolvimento ligado à tectônica do sal. Sua posição atual é bem definida pelo limite entre as maiores espessuras proximais e os depocentros mais descontínuos das minibacias distais.

$\mathrm{O}$ arcabouço interpretado e a análise de suas espessuras foram suficientes para construir um modelo evolutivo da área e estabelecer premissas da restauração estrutural.

\section{Restauração 2.5D Arestauração das seções extra-} poladas ao domínio 3D destaca alguns elementos da evolução estrutural relacionados à divisão estratigráfica discutida, bem como à metodologia de restauração adotada.

A restauração das camadas mais profundas reflete a precariedade do modelo estrutural e apresenta resultados pouco robustos. As falhas que definem o baixo estrutural apresentam maior rejeito no compartimento W. O maior movimento isostático neste compartimento pode ser interpretado como situação de maior estiramento litosférico. Comparando-se o relevo restaurado para o embasamento há 132 e 113 Ma e, no presente,

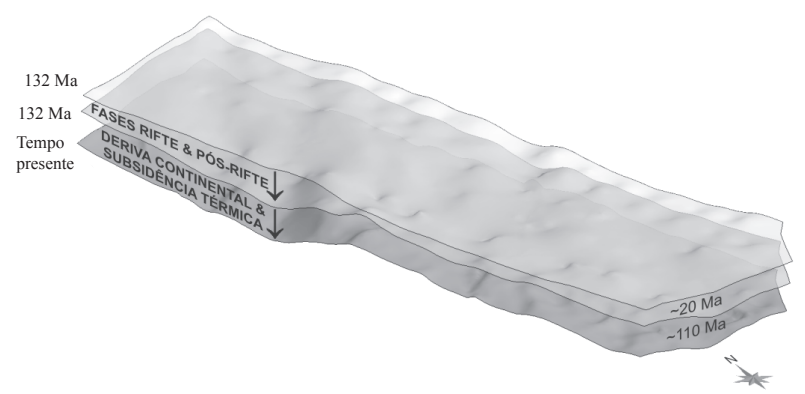

Figura 13 - Relevo do embasamento restaurado há 132 Ma, 113 Ma e no presente. observa-se o abatimento diferencial do baixo estrutural maior durante as fases rifte e pós-rifte (Fig. 13).

O cenário restaurado (visualizado nos ambientes $2.5 \mathrm{D}$ e $3 \mathrm{D}$ ) no momento anterior à deposição do sal há $113 \mathrm{Ma}$ (Fig. 14) ilustra a espessura sedimentar depositada entre 132 e 113 Ma. Uma linha tracejada realça a diferença de dois domínios estruturais. A Fig. 14 mostra um relevo com desníveis maiores que $2.000 \mathrm{~m}$, suficientes para acomodar a espessa camada de sal durante 1 Ma seguintes.

Os evaporitos preenchem o relevo preexistente, provocando importante resposta isostática na bacia (Fig. 15). O cenário sugere um desenvolvimento da bacia evaporítica a partir de dois depocentros independentes, separados pelo alto estrutural, posteriormente amalgamados em uma única bacia. As maiores espessuras ocorrem, novamente, no compartimento W, enquanto as menores, na região do alto estrutural.

A tectônica do sal tem início com a deposição dos carbonatos do Albiano e siliciclásticos do Cenomaniano (Fig. 16). Os primeiros diápiros se formam na região mais espessa do sal, em que o alto estrutural oferece a primeira resistência à movimentação. A configuração típica de evolução da bacia de Santos logo se estabelece, com a plataforma proximal mais espessa passando a depósitos mais delgados em águas profundas. Pequenas diferenças no avanço da plataforma e na compartimentação refletem incertezas - talvez imprecisões - de restauração. Um traço do que virá a ser a falha de Cabo Frio pode ser desenhado no pé do talude há $92 \mathrm{Ma}$, com a camada de sal subaflorando.

A deposição do Grupo Frade intensifica a progradação sedimentar (Fig. 17). Nas seções AA' e BB', ocorre compartimentação em torno dos diápiros,

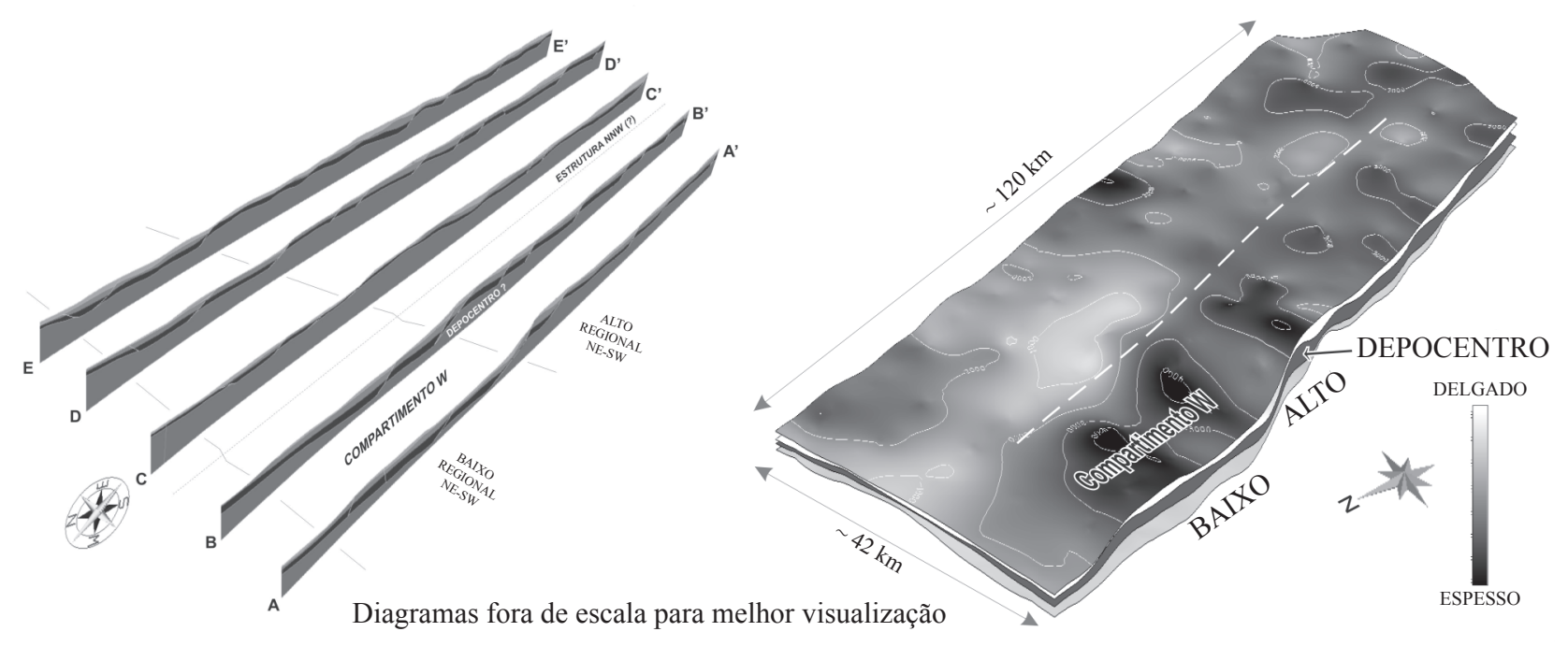

Figura 14 - Cenário restaurado há 113 Ma. 


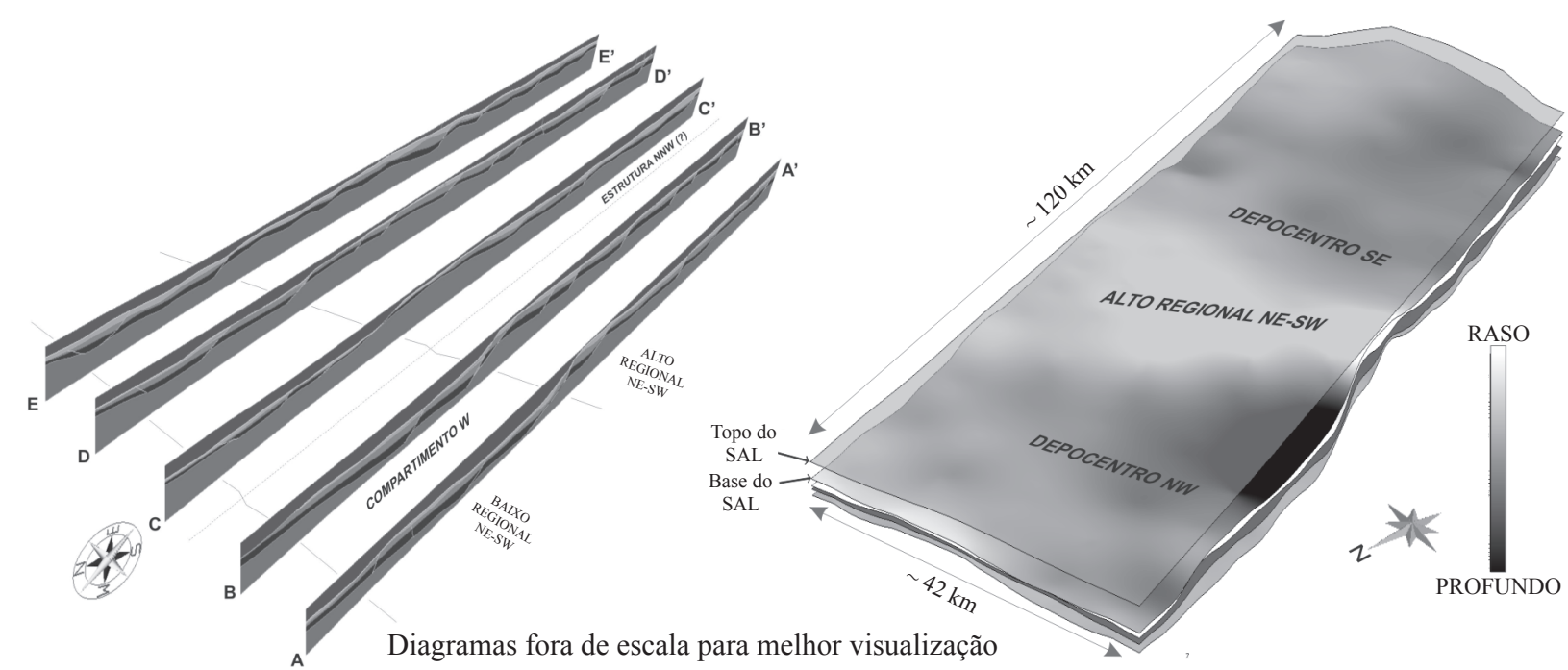

Figura 15 - Cenário restaurado após deposição do sal.

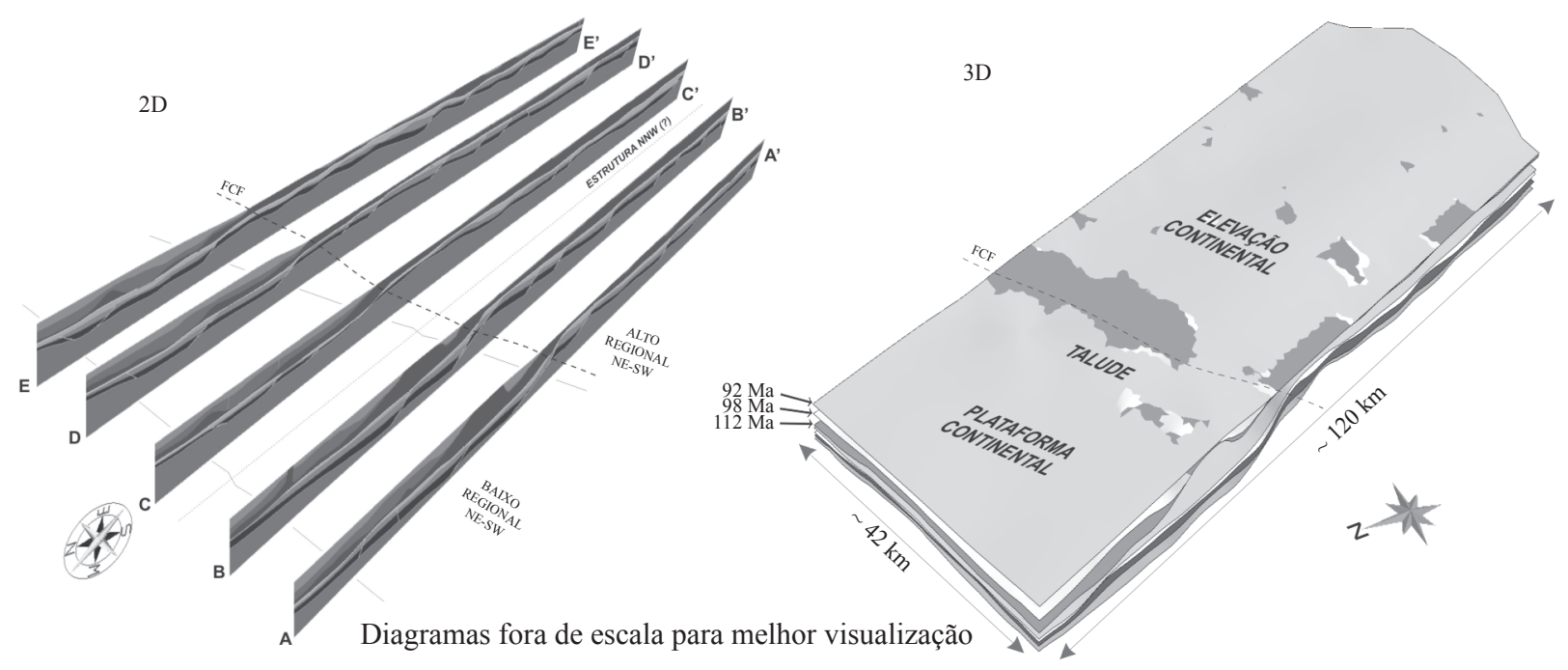

Figura 16 - Cenário restaurado há 92 Ma.

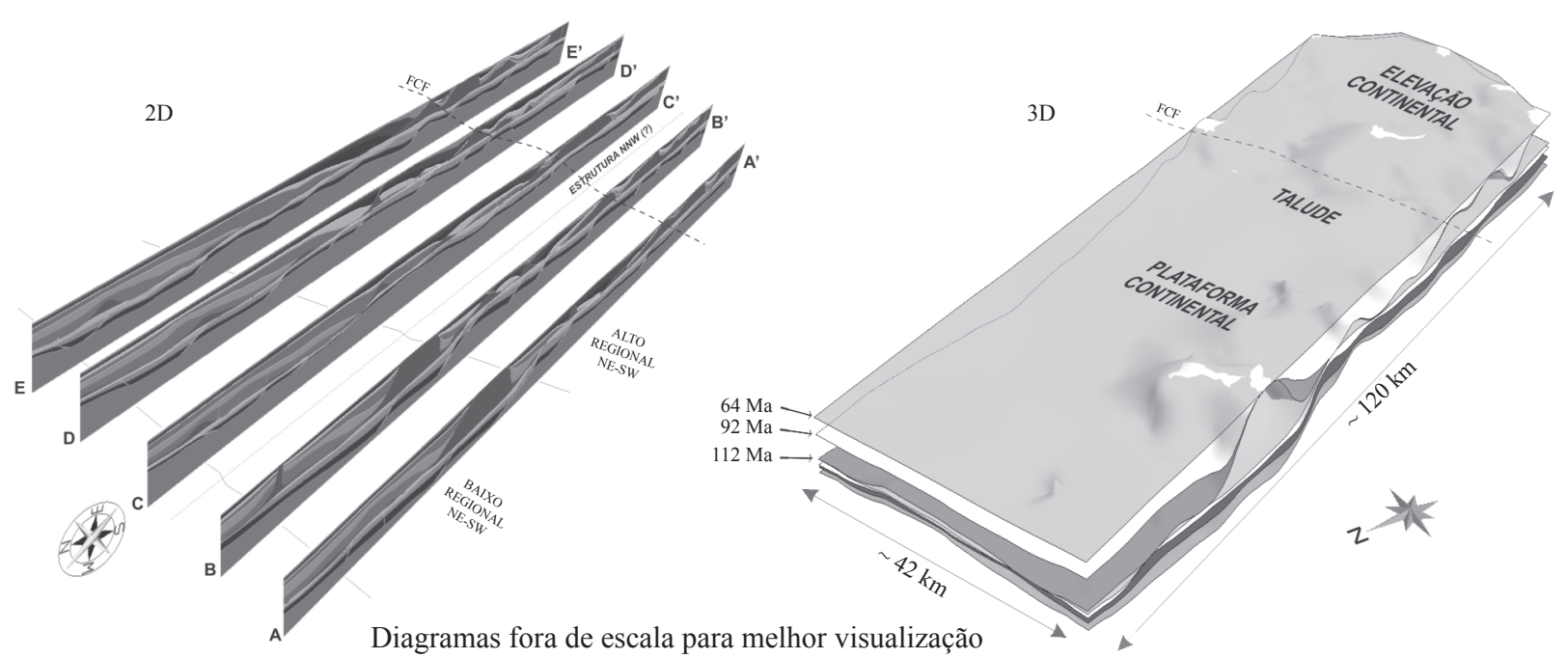

Figura 17 - Cenário restaurado do topo do Cretáceo há 64 Ma. 
alguns em condição subaflorante. A progradação se desenvolve em padrão antitético, mas sem complexidade na região das seções CC', DD' e EE'. A falha de Cabo de Frio, impulsionada pela sedimentação em trato de mar baixo, avança em torno de $50 \mathrm{~km}$ durante aproximadamente $30 \mathrm{Ma}$ (do Cenomaniano ao final do Cretáceo).

A falha de Cabo Frio desacelera seu avanço durante a deposição do Grupo Itamambuca e desloca-se menos de $5 \mathrm{~km}$ durante mais de $60 \mathrm{Ma}$ - retornando ao ponto de partida da restauração, o tempo presente (Fig. 18). A deformação do sal respondeu continuamente à sobrecarga sedimentar, porém não foi linear nem uniforme. Nas regiões proximais já havia muita restrição ao movimento, pois o sal deformado estava constrito pelas janelas formadas e a sobrecarga sedimentar como que ancorada na base do sal. Sem as limitações de mar baixo, predominava-se a agradação sedimentar. Na região mais distal, a compressão passa a compensar pequenos movimentos distensivos, principalmente na falha de Cabo Frio, e as minibacias experimentam um desenvolvimento mais intenso.
Mudanças de volume ao longo do tempo

As áreas do modelo 2D, dividido em três partes, sedimentos abaixo do sal (pré-sal), sal e sedimentos acima do sal (deriva), mostram-se correlacionáveis aos volumes do modelo 3D extrapolado (Tab. 1).

Em média, as áreas correspondem bem aos volumes. A área média da camada de sal é de 15\% em relação à área total e varia nas cinco seções entre 22 (seção AA') e 9\% (seção DD'). O volume médio de sal é de $16 \%$ em relação àquele total da área de estudo. Essa boa correlação se deve a superfícies obtidas por extrapolação suavizada que não representam detalhes tridimensionais da área de estudo.

Taxas de sedimentação foram calculadas a partir da área e de volumes. Os valores para o sal impressionam: mais de $1.200 \mathrm{~m}$ por Ma, dez vezes maior do que a taxa na sedimentação subjacente (Pré-sal) e 30 vezes maior do que nas unidades sobrepostas (fase de deriva).

A desaceleração da tectônica de sal pode ser analisada por meio das variações de volume de sal ao longo do tempo. A relação entre o sal e os sedimentos afetados pela tectônica adiastrófica se inicia em

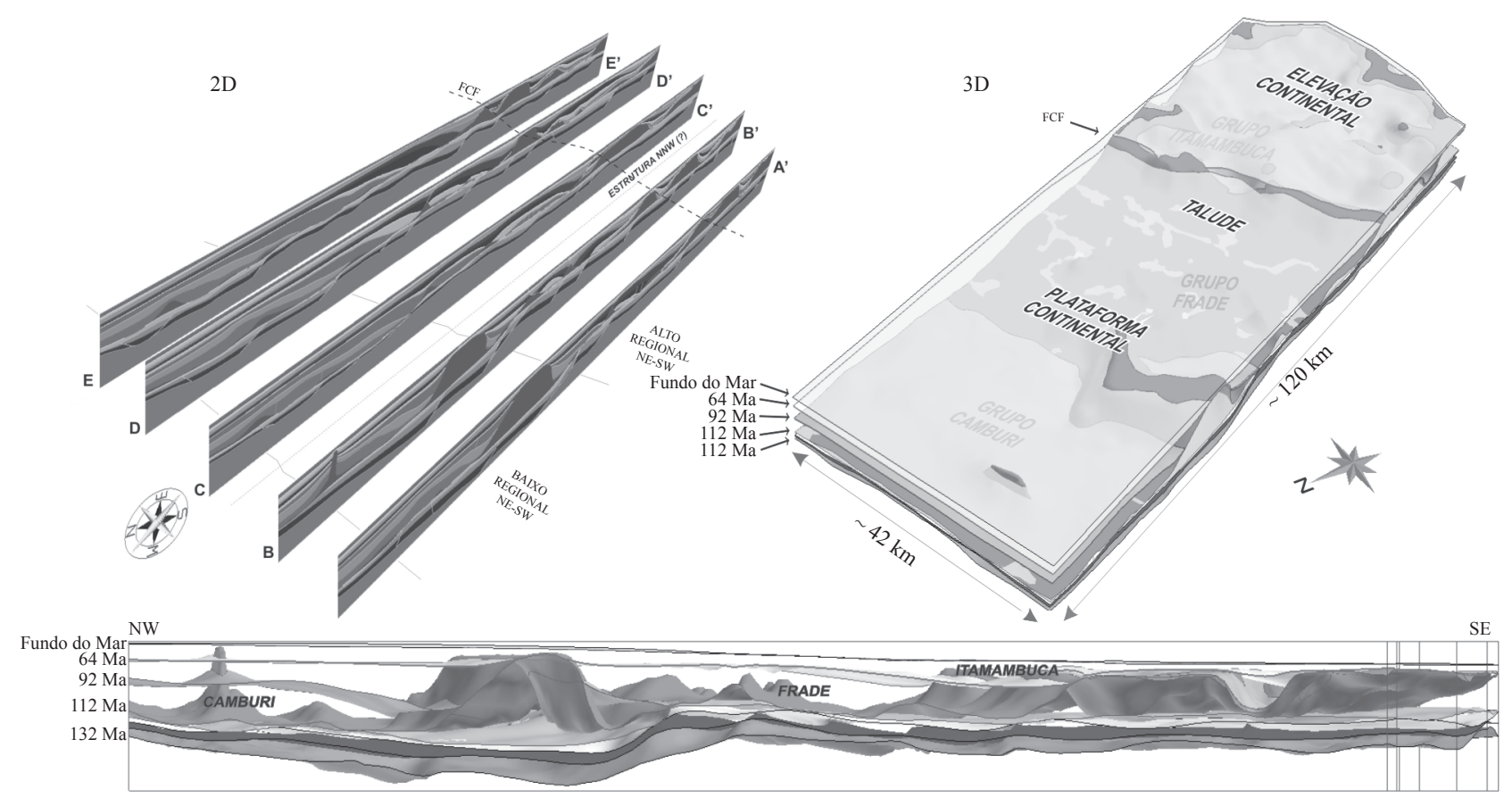

Figura 18 - Modelo baseado na interpretação sísmica.

Tabela 1 -Áreas das cinco seções, área média e volumes no presente

\begin{tabular}{lccccccc}
\hline Idade & Seção AA' & Seção BB' & Seção CC' & Seção DD' & Seção EE' & Média 2D & Volume 3D \\
\hline$(\mathrm{Ma})$ & $\left(\mathrm{km}^{2}\right)$ & $\left(\mathrm{km}^{2}\right)$ & $\left(\mathrm{km}^{2}\right)$ & $\left(\mathrm{km}^{2}\right)$ & $\left(\mathrm{km}^{2}\right)$ & $\left(\mathrm{km}^{2}\right)$ & $\left(\mathrm{km}^{3}\right)$ \\
\hline Deriva & 487 & 506 & 551 & 628 & 538 & 542 & 22.649 \\
\hline Sal & 219 & 196 & 131 & 88 & 105 & 148 & 6.422 \\
\hline Pré-sal & 311 & 324 & 227 & 268 & 262 & 278 & 11.325 \\
\hline
\end{tabular}


$100 \%$ sal e nada de outros sedimentos antes da deposição dos carbonatos albianos e termina em torno de $28 \%$ da área ou volume sedimentar no tempo presente. Conforme esta relação varia ao longo do tempo, o predomínio da reologia dúctil diminui. O volume de sal interpretado no tempo presente pode ser isolado do volume acrescido ao longo da restauração para recompor o sal expelido para regiões mais distais. A Tab. 2 e as Figs. 19 e 20 mostram as variações no modelo 3D em diferentes momentos. As inflexões observadas nas curvas evidenciam a correlação entre deformação e sedimentação, novamente coincidindo com os limites deposicionais entre os grupos Camburi, Frade e Itamambuca (92 e 64 Ma).
A restauração de seções foi realizada de forma independente, e nenhuma interação entre os resultados foi feita durante a restauração. É natural que diferenças na deformação restaurada sejam observadas entre uma seção e outra. A superposição dos topos restaurados para o sal em cada etapa oferece uma visão evolutiva da deformação (Fig. 21). No princípio, há $112 \mathrm{Ma}$, o topo do sal é quase plano. Ao final da deposição do Grupo Camburi (98 e $92 \mathrm{Ma}$ ), a deformação proximal já é intensa e as estruturas de sal aparecem ainda suaves. A falha de Cabo Frio e as feições compressivas ainda não são expressivas. A deposição do Grupo Frade (92 a $64 \mathrm{Ma}$ ) causa menos subsidência proximal, prograda a plataforma em direção à bacia

Tabela 2 - Medidas de áreas e volumes no modelo $3 D$

\begin{tabular}{lccccccccccc}
\hline Idades $(\mathrm{Ma})$ & 0 & 16 & 34 & 64 & 67 & 70 & 79 & 88 & 92 & 98 & 112 \\
\hline Volume de sal $\left(\mathrm{km}^{3}\right)$ & 6.347 & 6.386 & 6.502 & 7.111 & 7.396 & 7.501 & 7.916 & 8.274 & 9.467 & 9.370 & 9.799 \\
\hline Variação do presente $(\%)$ & $100 \%$ & $101 \%$ & $102 \%$ & $112 \%$ & $117 \%$ & $118 \%$ & $125 \%$ & $130 \%$ & $149 \%$ & $148 \%$ & $154 \%$ \\
\hline Volume expulso $\left(\mathrm{km}^{3}\right)$ & 0 & 11 & 53 & 248 & 397 & 668 & 1.135 & 1.516 & 2.507 & 3.033 & 3.549 \\
\hline Superfície de sal 3D $\left(\mathrm{km}^{2}\right)$ & 5.160 & 5.157 & 5.143 & 5.079 & 5.018 & 4.883 & 4.654 & 4.478 & 4.040 & 3.756 & 3.492 \\
\hline Taxa de distensão/área & $148 \%$ & $148 \%$ & $147 \%$ & $145 \%$ & $144 \%$ & $140 \%$ & $133 \%$ & $128 \%$ & $116 \%$ & $108 \%$ & $100 \%$ \\
\hline
\end{tabular}

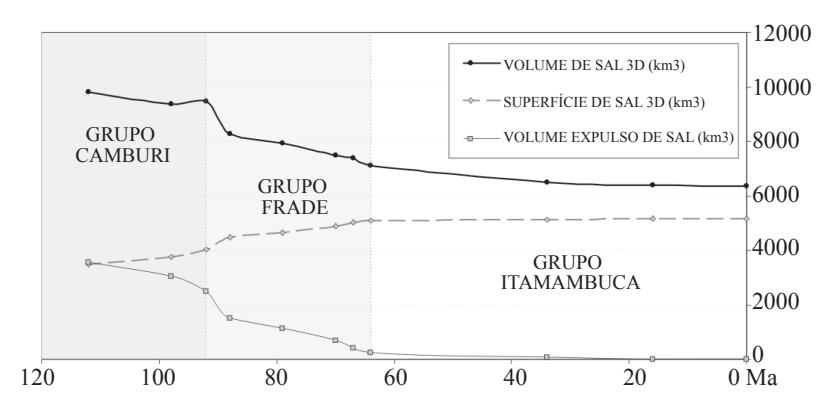

Figura 19 - Áreas e volumes de sal no modelo $3 D$.

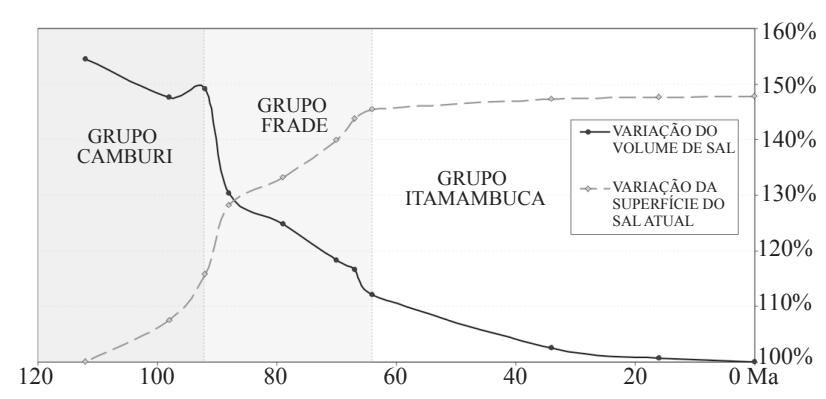

Figura 20 - Redução do volume de sal na área de estudo comparada ao avanço em área do sal atual.

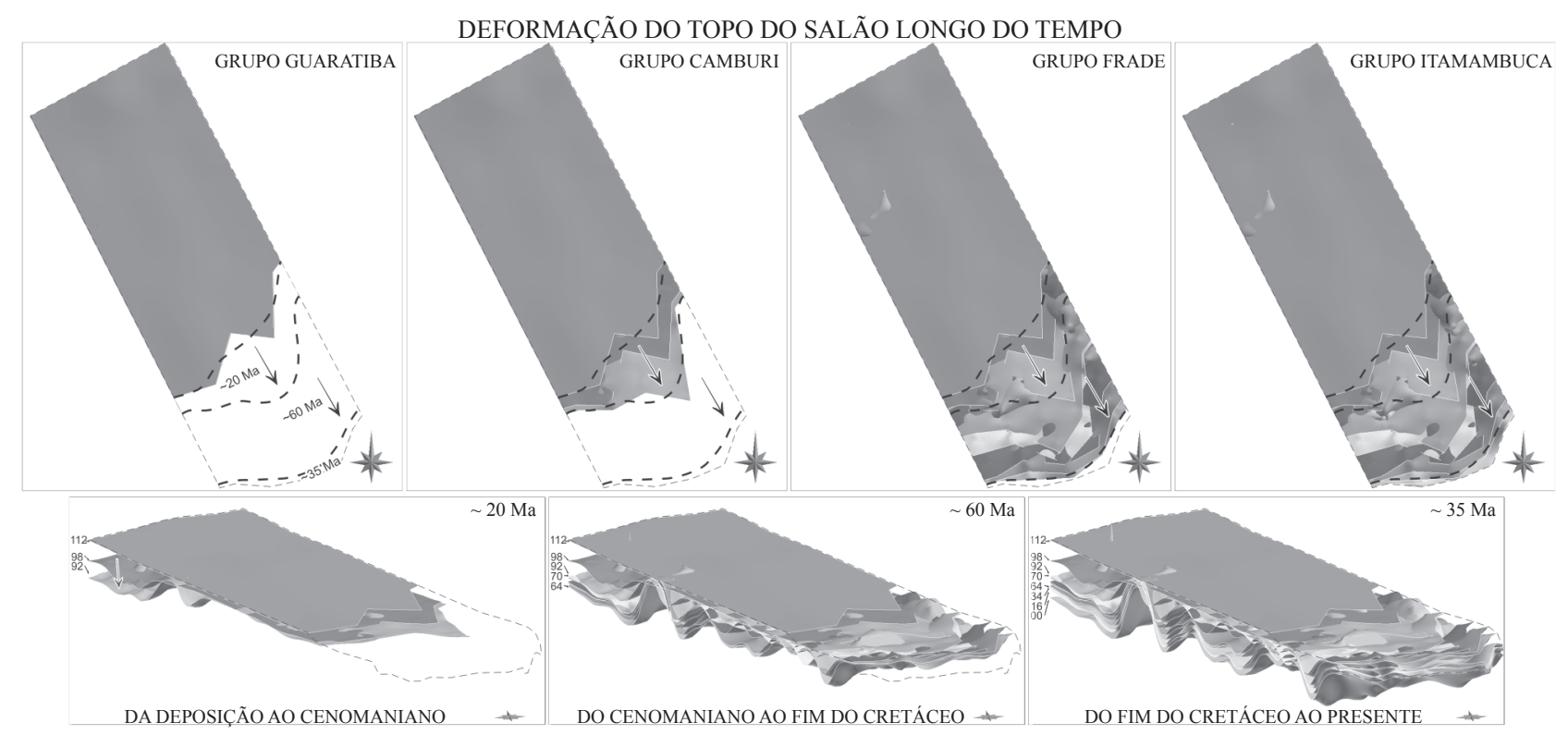

Figura 21 - Topo do sal em suas diferentes restaurações palinspásticas. 
coerentemente com Lavorante \& Ebert (2005) e cria janelas na camada de sal. Por fim, durante a deposição do Grupo Itamambuca (entre 64 Ma e o presente), a deformação compressiva se estabelece e a agradação sedimentar ocorre mais distribuída na área de estudo. Nas diferenças de distensão, as seções AA' e BB' parecem mais obstruídas pelo alto estrutural e pela estruturação precoce do sal no baixo estrutural, durante o Albiano e o Cenomaniano. A progradação durante o nível de mar baixo que provê um avanço mais linear em toda a área parece refletir a diminuição do papel destas estruturas no controle halocinético.

O desenvolvimento da falha de Cabo Frio está associado aos principais depocentros na área de estudo desde o Albiano (Fig. 22). Assim que espessos pacotes proximais do Grupo Camburi se depositam sobre os evaporitos, impulsionam-nos para 'reduzir' o espaço de acomodação distal. Um limite frágil entre um domínio espesso distensivo e outro delgado compressivo condicionam o desenvolvimento da falha.

Guerra (2008) faz alerta aos efeitos que a translação das estruturas (por dezenas de quilômetros em algumas situações) poderia causar à evolução dos sistemas petrolíferos. Os resultados sugerem grande translação relativa das estruturas de sal, mas também apontam padrões diferentes de distensão na deformação que ocorre nas fases rifte, pós-rifte e durante a de deriva. Desta forma, as principais rochas geradoras (estratigraficamente abaixo do sal) ficam relativamente imóveis, as janelas na camada de sal (principais elementos para migração secundária) são também relativamente estáticas e, do final do Cretáceo em diante, pouca movimentação lateral devido à tectônica do sal é prevista. Os resultados da restauração corroboram a avaliação de Araújo et al. (2005) de que $90 \%$ da deformação salífera na bacia de Santos ocorre até o final do Cretáceo. Para tais autores, o pico de expulsão de petróleo ocorreu no Campaniano superior e uma importante frente de migração se desenvolve de $44 \mathrm{Ma}$ até o presente. Os resultados sinalizam, portanto, pouco risco de sincronismo ao sistema petrolífero devido à tectônica de sal, mas a análise local de estruturas mais complexas não deve ser negligenciada em estudos específicos.

DISCUSSÃO Os resultados obtidos permitem uma análise sobre a evolução geológica da área de estudo e breves discussões, com destaque para as variações na camada de sal, organizadas a seguir.
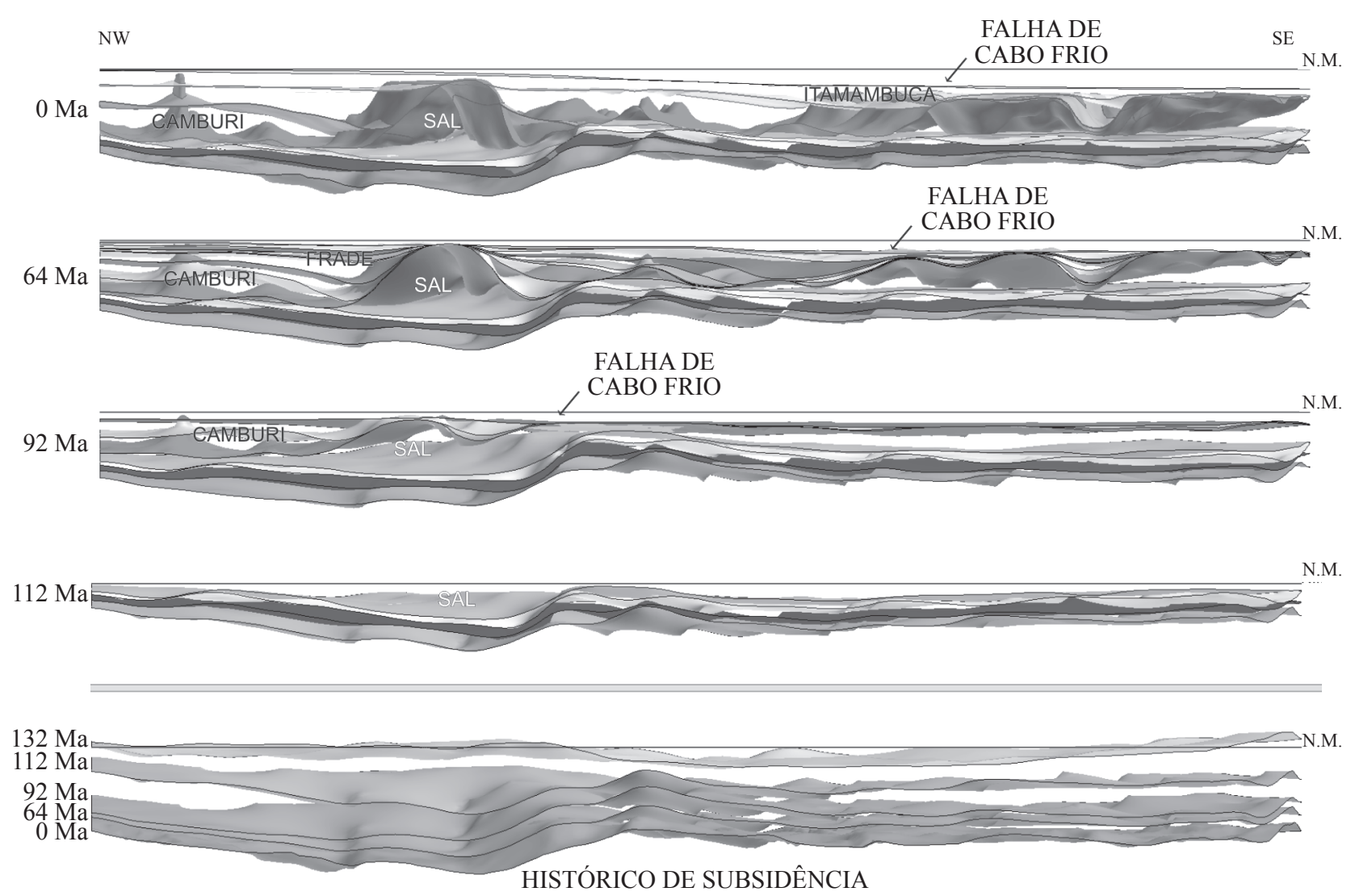

Figura 22 - Sequência de restauração há 0, 64, 92 e 112 Ma. Ilustração da subsidência do embasamento restaurado, do passado ao presente. 
Batimetria e isostasia nas restaurações $\mathrm{A}$ compensação flexural da isostasia é apenas parte dos movimentos verticais e demanda uma calibração paleobatimétrica após cada etapa de restauração. As incertezas dos dados bioestratigráficos são quase comparáveis aos erros acumulados nos cálculos isostáticos (Fig. 9). O aprofundamento das curvas na Fig. 9 reflete a maior incerteza na restauração da subsidência total do passado, mas, certamente, há fenômenos que não foram considerados nos cálculos. Um efeito não considerado é a eustasia, de menor magnitude. Outro desconsiderado é a variação térmica na litosfera durante a evolução da margem passiva ( $T_{e}$ constante). Isto equivale a desconsiderar um passado mais quente e a resposta reológica da litosfera mais suscetível à deformação. As diferenças isostáticas observadas para a variação de $T_{e}$ não justificaram estudos para um valor constante, entretanto sugerem a importância de sua variação no tempo em um estudo integrado.

Na incerteza da restauração de mais de $2.000 \mathrm{~m}$ de evaporitos e na magnitude da depressão necessária para acomodá-los (Montaron \& Tapponnier 2010, Garcia et al. 2012) entre 113 e 112 Ma, pode estar outra fonte maior das diferenças no cálculo isostático (Fig. 9). O aumento acentuado nas diferenças entre 112 e 92 Ma corresponde à maior intensidade da deformação halocinética, quando o Grupo Camburi é depositado sobre evaporitos dúcteis ainda muito espessos. Há muita incerteza na restauração destes cenários. Essa variação na isostasia concorre para a hipótese de Gonzaga (2005) de que o rifteamento tenha se prolongado durante o Albiano, embora tal postulação não seja corroborada pela abordagem de restauração. A mudança de padrão nos erros isostáticos entre 92 e 64 Ma coincide com a progradação do Grupo Frade e com o rápido avanço da linha de costa sob o trato de mar baixo (Moreira et al. 2007). Coincide também com o estabelecimento das primeiras janelas na camada de sal, ou seja, já não havia mais um sal proximal tão espesso para acomodar a sedimentação e se produz grande distensão lateral, nem tanto na vertical.

Nenhuma aplicação conhecida que utilize procedimentos estanques para descompactação e restauração recalcula a isostasia para o reposicionamento de cargas em situações de grande distensão lateral, a menos que se trabalhe com métodos de elementos finitos. Os 15 horizontes interpretados minimizam o erro acumulado. A restauração de uma camada de um fatiamento estratigráfico mais detalhado e delgado minimiza o erro isostático acumulado e a descompactação diferencial. Representa uma deformação menor à cada etapa de restauração e, consequentemente, um desvio menor para a descompactação seguinte.

\section{Restauração estrutural e integração 2D/3D Por} mais que a halocinese seja complexa, sendo o sal incompressível, somente a dissolução pode alterar efetivamente o volume de sal. O melhor controle de restauração foi partir de um modelo de deformação e fluxo. Se o sal responde à sedimentação, uma tendência de escape e variação de volume pode ser estabelecida. A área de estudo contrabalança depocentros mais significativos na parte proximal à minibacias distais, tendo um alto estrutural como elemento perturbador da deformação na transversal ao transporte tectônico. Assumindo desvios neste balanço, a premissa de conservação da área para a camada de sal representa a busca de uma ferramenta de controle local para a restauração. Em outras palavras, o sal responde proporcionalmente ao quanto é impulsionado pela progradação e acumulado sob as minibacias distais (Fig. 22). Esta proporcionalidade se expressa na conservação de área sob o domínio desta compensação.

Enquanto Mohriak \& Szatmari (2001) interpretaram a grande lacuna (gap) do pacote Albiano (dezenas de $\mathrm{km}$ ) na falha de Cabo Frio como resultado da distensão com enormes deslocamentos acumulados, Ge et al. (1997) propuseram uma lacuna deposicional devido à inflação distal da camada de sal em função da carga de sedimento proximal. A restauração sugere uma composição destes fatores, deslocamento lateral sindeformacional e sedimentação distal restrita para o desenvolvimento desta lacuna.

CONCLUSÕES E PERSPECTIVAS A restauração estrutural $2.5 \mathrm{D}$ integrada à análise volumétrica e espacial se mostrou ferramenta poderosa para o aprendizado e para a compreensão da tectônica de sal na porção central da bacia de Santos.

A restauração produziu um cenário evolutivo bem correlacionado ao arcabouço estratigráfico.

A subsidência obtida em restauração foi mais significativa nas fases rifte e pós-rifte (Grupo Guaratiba), particularmente sobre o baixo estrutural proximal, região estruturalmente fragilizada que acomoda as maiores espessuras, inclusive do sal aptiano. A instalação de espessa plataforma sobre este 
baixo controlou o deslocamento lateral do sal, produzindo espaço de acomodação para a fase drifte, desde a chegada dos primeiros sedimentos no Albiano (Grupo Camburi). Ao final do Cenomaniano, a camada de sal já não encontra tanta facilidade para se deslocar e acomodar a deposição do Grupo Frade e, sob trato de mar baixo, a plataforma avança em direção à bacia. A partir do Paleoceno, o sal tem sua mobilidade lateral praticamente anulada, com janelas bem estabelecidas, deforma-se menos e acomoda a deposição do Grupo Itamambuca predominantemente por agradação.

Os quatro grupos estratigráficos diferenciaram-se em diversos aspectos controlados da restauração (isostasia, falhas, diapirismo, movimentação lateral etc.). A transição entre diferentes padrões de sedimentação e deformação foi crítica na restauração, e as discordâncias que separam os grupos Camburi, Frade e Itamambuca ficaram bem remarcadas nas divergências analisadas entre as cinco seções restauradas e na área de estudo.

O controle estrutural também ficou claro na restauração. A deformação foi predominantemente vertical nas fases rifte/pós-rifte e lateral, na halotectônica. Cerca de 50\% da subsidência no compartimento $\mathrm{W}$ do baixo estrutural ocorreu durante as fases rifte e pós-rifte. A subsidência térmica da fase drifte ficou mais homogeneamente distribuída. As taxas de distensão $\beta$ foram significativamente maiores na deformação halocinética e diferenciadas na direção de transporte por estruturas preexistentes NE-SW.

Os resultados validaram a conservação material do sal como opção de controle da restauração da área de estudo, pois a redistribuição do sal assim restaurado estabeleceu relações coerentes para as taxas de distensão e sedimentação.

Os resultados dos ensaios e da restauração palinspástica deixaram claro que os programas não compensam os efeitos correlatos de isostasia, batimetria, descompactação e deslocamento lateral em seus cálculos e procedimentos. $\mathrm{O}$ trabalho apontou um ferramental de cálculo integrado destes fenômenos como perspectiva de desenvolvimento para eliminar os erros acumulativos observados em um tratamento em separado. Os resultados sugerem igualmente a consideração dos efeitos térmicos da ruptura litosférica bem como da eustasia ao longo do tempo e do espaço para ampliar a compreensão dos fenômenos observados.

AGRADECIMENTOSProfunda gratidão à Petrobras pela permissão para publicação do artigo, com sinceros agradecimentos à Sylvia Anjos e Henrique Penteado. Aos colegas e amigos Gilvan Hamsi e Marta Guerra pelos comentários, sugestões e revisão do artigo.

\section{Referências}

Almeida F.F.M. 1976. The system of continental rift bordering the Santos Basin, Brazil. Anais da Academia Brasileira de Ciências, 48(Suppl):15-26.

Araujo L.M., Garcia S.F.M., Queiroz C.L., Cortez M.M.M., Saito M. 2005. A 4-D petroleum system model in a southern area in the Santos Basin, Brazil. In: ALAGO, Workshop Basin Modeling, 4, Abstracts, 3 p.

Assine M.L., Correa F.S., Chang H.K. 2008. Migração de depocentros na bacia de Santos: importância na exploração de hidrocarbonetos. Revista Brasileira de Geociências, 38:111-127.

Bender A.A., Mello U.T., Chang H.K. 1989. Reconstituição bidimensional da história geológica de bacias sedimentares: teoria e uma aplicação na bacia de Campos. Boletim de Geociências da Petrobras, 3:67-85.

Carminatti M., Wolff B., Gamboa L.A.P. 2008. New exploratory frontiers in Brazil. In: World Petroleum Congress, 19, Proceedings, $11 \mathrm{p}$.

Chang H.K., Kowsmann R.O., Figueiredo A.M.F. 1990 Novos conceitos sobre o desenvolvimento das bacias marginais do leste brasileiro. In: Raja Gabaglia G.P. \& Milani E.J. (eds) Origem e evolução de bacias sedimentares, Petrobras, p. 269-289.

Cobbold P.R. \& Szatmari P. 1991. Radial gravitational gliding on passive margins. Tectonophysics, 188:249-289.

Demercian L.S. 1996. A halocinese na evolução do sul da bacia de Santos do Aptiano ao Cretáceo superior. Dissertação de Mestrado, Universidade Federal do Rio Grande do Sul, 201 p.

Domzig A., MacLean S., Waltham D., Rice T., Shackelton R. 2010.3D structural restoration and forward turbidite modelling. Disponível em: http://www.mve.com/ abstracts/detail/3d-structural-restoration-and-forwardturbidite-modelling. Acessado em: 01/09/2011.

Freitas J.T.R. 2006. Ciclos deposicionais evaporíticos da bacia de Santos: uma análise cicloestratigráfica a partir de dados de 2 poços e de traços de sísmica. Tese de Doutorado, Instituto de Geociências, Universidade Federal do Rio Grande do Sul, 159 p. 
Garcia S.F.M. 1999. Estudo tridimensional de efeitos da halocinese em margens passivas. Dissertação de Mestrado, Universidade Federal de Ouro Preto, 167 p.

Garcia S.F.M., Letouzey J., Rudkiewicz J.L., Danderfer A., Frizon de Lamotte D. (2012). Structural modeling based on sequential restoration of gravitational salt deformation in the Santos Basin (Brazil). Marine \& Petroleum Geology, Disponível em: http://www.sciencedirect.com/science/article/pii/ S0264817212000438. Acessado em: 09/02/2012.

Ge H., Jackson M.P.A., Vendeville B.C. 1997. Kinematics and dynamics of salt tectonics driven by progradation. In: AAPG, Bulletin, 81:398-423.

Gonzaga F.G. 2005. Simulação geoquímica 1D ao longo de uma seção geológica na bacia de Campos. Dissertação de Mestrado, Instituto Alberto Luiz Coimbra de PósGraduação e Pesquisa de Engenharia, Universidade Federal do Rio de Janeiro, 85 p.

Gomes P.O., Parry J., Martins W. 2002. The outer high of the Santos Basin, Southern São Paulo Plateau, Brazil: tectonic. In: AAPG, Hedberg Conference: Hydrocarbon Habitat of Volcanic Rifted Passive Margins, Abstracts, 5 p.

Grando G., Schleder Z., Shackleton R., Seed G., Buddin T., McClay K., Borraccini F. 2009. 3D structural evolution of the salt controlled frampton anticline, atwater valley fold belt, deep water Gulf of Mexico. Disponível em: http://www. searchanddiscovery.com/documents/2009/50161 grando/ ndx_grando.pdf. Acessado em: 01/09/2011.

Guerra M.C.M. 2008. Role of halokinesis in controlling structural styles and sediment dispersal pattern in the Santos Basin, offshore SE Brazil. Tese de Doutorado $(\mathrm{PhD})$, University of Edinburgh, $270 \mathrm{p}$.

Guimarães P.P., Almeida H.P., Kowsman R.O., Costa M.P., Boa Hora M.P. 1982. Modelagem gravimétrica na porção sul do platô de São Paulo e suas implicações geológicas. In: SBG, Congresso Brasileiro de Geologia, 32, Anais, p. 1570-1575.

Hughes M. \& Davison I. 1993. Geometry and growth kinematics of salt pillows in the southern North Sea. Tectonophysics, 228:239-254.

Jenyon M.K. 1986. Salt tectonics. London, Elsevier, 191 p.

Lavorante P.L. \& Ebert H. D. 2005. Reconstrução paleogeográfica 3D das bacias de Santos e Campos: do Albiano ao Maastrichtiano. In: Congresso Brasileiro P\&D Petróleo e Gás, 3, Trabalhos técnicos, 6 p.

Mascle J.R. \& Renard V. 1976. The marginal Sao Paulo Plateau, comparison with the southern Angolan margin. Anais da Academia Brasileira de Ciências, 48:179-190.

Mohriak W.U. 2001. Salt tectonics, volcanic centers, fracture zones and their relationship with the origin and evolution of the South Atlantic Ocean: geophysical evidence in the Brazilian and West African margins. In: SBGF, International Congress, 7, Expanded Abstract, p. 1594.
Mohriak W.U. \& Szatmari P. 2001. Salt tectonics and sedimentation along Atlantic margins: insights from seismic interpretation and physical models. In: GSA, Memoir, 193:131-151.

Montaron B. \& Tapponnier P. 2010. A quantitative model for salt deposition in actively spreading basins. Disponível em: http://www.searchanddiscovery.com/ documents/2010/30117montaron/ndx_montaron.pdf. Acesso em: 01/09/2011.

Moreira J.P., Madeira C.V., Gil J.A., Machado M.A.P. 2007. bacia de Santos. Boletim de Geociências da Petrobras, 15:531-549.

Peel F.J., Travis C.J., Hossack J.R. 1995. Genetic structural provinces and salt tectonics of the Cenozoic offshore U.S. Gulf of Mexico: a preliminary analysis. In: Jackson M.P.A., Roberts D.G., Snelson S. (eds.) Salt tectonics: a global perspective. Memoir, 65, AAPG, p. 153-175.

Richards D.R., Calvert S.J., Yamamoto H. 2003. 2D and 3D structural balancing in a deformed foreland basin, Peruvian Subandean Belt. In: ACGGP, Simposio Bolivariano Exploración Petrolera en las Cuencas Subandinas, 8, Anais, p. 141-146.

Roberts A.M., Kusznir N.J., Yielding G., Styles P. 1998. 2D flexural backstripping of extensional basins: the need for a sideways glance. Petroleum Geoscience, 4:327-338.

Rowan M.G. 1993. A systematic technique for the sequential restoration of salt structures. Tectonophysics, 228:331-348.

Santi M.R. 2002. Procedimentos computacionais para $o$ balanceamento de seções geológicas. Tese de Doutorado, PUC Rio de Janeiro, 168 p.

Talbot C.J. 1995. Moulding of salt diapirs by stiff overburdens. In: Jackson M.P.A., Roberts D.G., Snelson S. (eds.) Salt tectonics: a global perspective. Memoir, 65, AAPG, p. 61-75.

Watts A.B. 2001. Isostasy and flexure of the lithosphere. Cambridge University Press, Cambridge, 458 p.

Zalán P.V. \& Oliveira J.A.B. 2005. Origem e evolução estrutural do sistema de riftes cenozóicos do Sudeste do Brasil. Boletim de Geociências da Petrobras, 13:269-300.

Zalán P.V., Severino M.C.G., Oliveira J.A.B., Magnavita L.P., Mohriak W.U., Gontijo R.C., Viana A.R., Szatmari P. 2009. Stretching and thinning of the upper lithosphere and continental-oceanic crustal transition in Southeastern Brazil. In: AAPG, International Conference and Exhibition, Abstracts, 1 p.

Manuscrito ID: 24156

Recebido em: 27/09/2011 Aprovado em: 07/03/2012 